\title{
Why Can Weak Linkages Cause International Stock Market Synchronization? The Mode-Locking Effect
}

\author{
Larry Filer $^{1} \&$ David D. Selover ${ }^{1}$ \\ ${ }^{1}$ Department of Economics, Old Dominion University, VA, US \\ Correspondence: David D. Selover, Department of Economics, Old Dominion University, 5115 Hampton Boulevard, \\ Norfolk, VA 23529, US. Tel: 757-683-3541. E-mail: dselover@odu.edu
}

Received: April 25, 2014

Accepted: May 23, $2014 \quad$ Online Published: May 30, 2014

doi:10.5430/ijfr.v5n3p20

URL: http://dx.doi.org/10.5430/ijfr.v5n3p20

\begin{abstract}
This study investigates the synchronization between stock markets in different countries. International stock markets tend to synchronize with one another in what appears to be an international financial cycle, yet trade and capital flows between the stock markets do not appear to be strong enough for one stock market to "drive" fluctuations in another stock market. Why are these weakly linked financial markets synchronized? This study suggests that global stock market synchronization results from a "mode-locking" phenomenon, a nonlinear process in which even a weak coupling between oscillating systems like stock markets tends to synchronize the fluctuations between the systems. Simulations, econometric analysis, and spectral analysis investigate this mode-locking hypothesis. Analysis reveals modest support for the mode-locking hypothesis of international stock market synchronization.
\end{abstract}

Keywords: international stock markets, stock market synchronization, mode-locking, phase-locking, financial market synchronization, financial linkages, international business cycles

\section{Introduction}

Observing the graphs of the major national stock markets, one is struck by their tendency to synchronize. In this study we investigate the mechanism behind the synchronization of fluctuations in different national stock markets. Why do the stock markets of different countries tend to synchronize? The linkages between them include trade linkages, financial linkages and common expectations. But these stock markets are not directly linked via some accounting or mechanical mechanism. The linkages between these stock markets are not rigid, but are variable, multi-channeled, indirect, weak, nonlinear, complex, and subject to stochastic shocks. Under the circumstances, it is not clear how one stock market might drive another. So the main question addressed here is, how can such multi-channeled, indirect, flexible, weak, and unpredictable linkages cause international stock markets to synchronize? One answer is that the non-linear "mode-locking" phenomenon can cause international stock markets to synchronize, even if the linkages between the markets are relatively weak. In addition, we note that international herd behavior, such as found in financial markets, can give rise to a mode-locking mechanism and bring about synchronization between markets, as shown by Sussmuth $(2002$, 2003). The question is an important question because a synchronization of stock market returns can diminish the benefits of international financial diversification.

The linkages between stock markets are quite complex. There are several potential channels for linkage: Trade linkages between countries can serve as one of the channels through which shocks might be transmitted from market to market. World-wide periods of investor optimism or pessimism may synchronize the markets in what some call a "contagion" effect. Common global shocks due to important world events, such as an oil shock or war might tend to bring about synchronization. Capital flows from one country to another in the form of foreign investment might help cause synchronization.

We do not here attempt to determine the precise transmission channels. The question addressed here is, how can weak and variable linkages cause international stock markets to synchronize? We propose the hypothesis that the various stock markets of the world economy are synchronized through a nonlinear "mode-locking" effect in which the cycles of different stock markets are synchronized through the relatively weak linkages between the stock markets. In this model, a dominant stock market does not have to "drive" the cycles in another stock market. The linkages between stock markets merely have to be strong enough to affect the timing of movements in other markets. In the mode-locking phenomenon, if the linkage is strong enough, the cycles of the various stock markets are quickly 
brought into synchronization with each other. If the stock markets are too weakly linked, then the two stock markets will continue to fluctuate in an unsynchronized fashion. However, if the linkage exceeds a certain threshold value, then the nonlinear mutual self-correcting properties of the stock markets engage, and the two (or more) stock markets will tend to synchronize. This is called a state of "mode-lock." This mode-locking may occur even if the original inherent frequencies of the fluctuations in the two stock markets are different and even if the markets are subject to a great deal of noise and strong random shocks. (Note 1) The assumptions behind mode-locking include the existence of some periodic deterministic components in the markets (even with strong stochastic components), the presence of some nonlinearities, and a strength of linkage exceeding some threshold value (which can be quite weak).

In this paper we present a mathematical model of mode-locking and use it to illustrate and simulate the mode-locking phenomenon. We systematically examine the returns from various stock markets around the world and test them statistically for the assumptions and implications of the mode-locking phenomenon. In our analysis we find modest evidence in favor of the mode-locking explanation of international stock market synchronization. Using graphs and correlations we find a significant amount of comovement between certain stock markets. We find some evidence of Granger causality between certain markets. The research of Canova and De Nicolo (1995), Fama (1981, 1990), and others provides evidence of deterministic components in the stock market returns. A set of F-tests supplies evidence for the presence of nonlinearities in the stock market returns. Using spectral analysis we find evidence of periodicity existing in the stock markets and similarity in modal frequencies. And finally, using cross-spectral analysis we find evidence of a convergence of certain stock markets on common frequencies. We build our case for the existence of mode-locking by observing, measuring, and testing a number of the assumptions and implications of mode-locking.

The paper is unique inasmuch as it is the first paper to apply the phenomenon of mode-locking to international stock markets and to point out how weak shocks between stock markets can bring about a synchronization of those markets. It is important because it can explain why international financial markets are increasingly synchronized.

Section 2 provides a literature review of the synchronization of international stock markets and a brief review of the mode-locking literature. Section 3 formalizes a simple model to illustrate the mode-locking mechanism. Section 4 demonstrates some simulations of the mode-locking mechanism. Section 5 reports the empirical evidence for mode-locking between different national stock markets, and Section 6 summarizes the findings.

\section{Literature Review}

\subsection{Interdependence of International Stock Markets}

There is a large literature examining the interdependence between stock markets around the world. There are several major empirical approaches to this synchronization of financial markets research. Most of the research uses some form of correlations and regressions in an attempt to measure the strength of stock market co-movements over time. One of the earliest studies was by Grubel (1968) who found that international stock markets were weakly correlated and that there are economic benefits to be gained from international portfolio diversification. Eun and Shim (1989) used VARs to find that stock market interdependence has increased over time and that the US market has a significant influence on other national stock markets.

Karolyi and Stulz (1996) used correlations, instrumental variables, and GARCH models to analyze the relation between the prices of US stocks and the prices of Japanese stocks and found that the transmission between international markets is greatest in times of high market volatility, a conclusion that tends to support the contagion hypothesis. Bekaert, Harvey, and Ng (2005) used a world CAPM model to test for international contagion effects. They did not find evidence of contagion during the Mexican Crisis of 1994, but did find evidence of possible contagion during the Asian Crisis of 1998. Kizys and Pierdzioch (2009) constructed a time-varying parameter model of stock returns and found that macroeconomic shocks did not have a systematic effect on the international synchronization of stock markets.

King and Wadhwani (1990) investigated the relationship between the New York and London stock markets and concluded that a rise in the inter-market correlation after the 1987 stock market crash was evidence of a contagion effect. However, Forbes and Rigobon $(2001,2002)$ noted that high volatility naturally causes higher correlations, and when they corrected inter-market correlations for volatility, they found that the correlations were fairly constant over the sample period, thus providing evidence against the contagion hypothesis.

Pretorius (2002), Flavin, Hurley, and Rousseau (2002), Quinn and Voth (2008), Beine and Candelon (2007), and Asgharian, Hess, and Liu (2013) used different forms of the gravity model to analyze bi-national stock market correlations and have found trade linkages to be a very strong determinant of international stock market interdependence. This finding is supported by Lahrech and Sylwester's (2013) finding that the implementation of the 
NAFTA agreement increased the correlations between the US and Mexican, and the Canadian and Mexican stock markets. Asgharian et al (2013) used a spatial form of the gravity model and found that spatial dependencies and proximity matter for stock market synchronization. Liu (2013) created a dynamic panel gravity model of stock market correlations and found that telephone and internet information capacity and industrial structure similarities can help explain the stock market synchronization. Forbes and Chinn (2004) decomposed stock market returns into global, industrial sector, and cross-country factors and found that direct international trade linkages are the most important mechanism for international financial transmission. This would suggest that national business cycles and trade in goods and services are partly behind the propensity for stock markets to synchronize. Lucey and Zhang (2010) employed a gravity model and found that culture matters and that the smaller the cultural distance between two countries, the closer their stock markets tend to correlate.

Hamao, Masulis, and Ng (1990), Karolyi and Stulz (1996), and Ramchand and Susmel (1998) used a variety of GARCH models to measure the transmission of mean returns and volatility from one market to another, and these studies have found evidence of a significant international transmission of stock market volatility. Hu et al (1997) studied volatility spillovers in East Asia. Using a bivariate GARCH model, Berben and Jensen (2005) found that while international stock markets have become more correlated over time, no particular dominant industrial sectors were responsible for that increasing correlation.

Granger and Morgenstern (1970) used cross-spectral analysis and found national stock markets to move independently over 1961 - 1964. But Hilliard (1979) used spectral and cross-spectral analysis over 1973 - 1974 and found close linkages among stock markets around the world. Rua and Nunes (2009) examined stock market interdependence using wavelet analysis and found that the strength of the stock market correlations is stronger at lower frequencies.

From all of this research there have emerged several main findings. There does appear to be a substantial amount of co-movement and synchronization between international stock markets. The synchronization appears to have increased over time. The US stock market appears to have a dominant influence upon stock markets around the world. Locational and regional effects are statistically significant at explaining much of the stock market co-movments. Cultural similarity, industrial similarity, and telecom capacity also explain part of the synchronization. Research using GARCH models reveals a significant amount of transmission of stock market volatility between international stock markets. Countries with strong trading relationships tend to show more co-movement between their stock markets. However, none of these studies explains why these relatively weak and indirect linkages are sufficient to bring about synchronization between stock markets around the world.

\subsection{The Mode-Locking Phenomenon}

In nonlinear dynamics, the classical illustration of mode-locking is the story of the Dutch physicist, Christiaan Huygens' $(1629-1695)$ collection of pendulum clocks which hung side by side on a beam in his room, but which were otherwise unconnected. (Note 2) Initially the pendulum clocks oscillated at similar but not identical frequencies and were not synchronized. However, due to the very weak vibrations transmitted from clock to clock through the beam, after a period the clocks tended to lock into synchronization with each other. This phenomenon occurred even though the two clocks were extremely weakly linked and the inherent frequencies of the clock pendulums were somewhat different. Although neither clock necessarily drives the other, they may transmit weak but just strong enough impulses from one clock to another that affect the timing of the clocks, and bring about synchronization. The mode-lock may drive the pendulums to synchronize exactly in phase or with a small phase difference or timing lag. This phenomenon may also describe the interaction between the fluctuations of different national stock markets.

"Mode-locking" is a nonlinear phenomenon in which very weak linkages between oscillating systems can bring about a synchronization of those systems. The phenomenon is not widely known in economics, and the literature on mode-locking in economics is still fairly modest. Strogatz $(1994,2003)$ provides a good background and a detailed explanation of the phenomenon. The earliest applications of the mode-locking phenomenon to economics appear in papers by Mosekilde, Larsen, Sterman, and Thomsen (1992, 1992), Mosekilde, Thomsen, and Sterman (1992), Weser (1992), and Woitek (1996). Krugman (1996) suggested the application of mode-locking to business cycle synchronization, and a number of people have applied the concept of mode-locking to international business cycle synchronization, including Selover and Jensen (1999), Sussmuth (2002), Anderson and Ramsey (2002), and Sussmuth and Woitek (2004), among others. Selover, Jensen, and Kroll $(2003,2005)$ and Sussmuth and Woitek (2005) have shown how mode-locking can enforce the synchronization of industrial sectors and regions.

Scharfstein and Stein (1990) suggested "herd behavior" in stock markets might cause financial investors' decisions to be more correlated. Significantly, Sussmuth $(2002,2003)$ constructed a model of investment based on herd 
behavior and showed how herd behavior can give rise to mode-locking and a consequent synchronization of sectors of an economy. Such a model could quite easily be applied toward explaining how herd behavior between investors in different national financial markets might cause their stock markets to synchronize via the mode-locking phenomenon.

\section{The Model}

Mode-locking is a synchronization phenomenon in which two or more weakly linked oscillators (in this case stock markets) with different inherent frequencies can lock-on to one another and move into synchronization at a compromise frequency usually between the inherent frequencies of the two systems. If the coupling between the two oscillators exceeds a certain modest threshold, a qualitative switch occurs, the system mode-locks, and the oscillators synchronize. If the linkage is weaker than the threshold, there is no mode-lock and no synchronization. When mode-locking occurs there is a continuous adjusting force that tends to pull the two signals into synchronization at a common frequency, usually with a slight lag or phase difference.

What makes this model compelling is three things. First, it is important to note that the mode-locking phenomenon is ubiquitous and is responsible for much of the synchronization in the world around us. The mode-locking phenomenon is more common than we might think, and it is applicable to many phenomena, including the synchronization of mating fireflies (Strogatz $(1994,2003)$ ), the synchronization of the movements of schools of fish, the mode-locking (or "phase-locking") of light waves in a laser, the synchronization of international business cycles, the coordination and synchronization of musicians in an orchestra, and numerous other examples. Second, it should be noted that mode-locking must occur under certain circumstances. If the systems of interest display some degree of deterministic periodic behavior, and if the linkages between the oscillating systems exceed certain modest thresholds, then mode-locking behavior must occur and the oscillators must tend to synchronize, (although possibly with a lag or phase difference). There must be some nonlinearities present in the system for mode-lock to occur. Thirdly, the model is appealing because it can be linked to herd behavior. Sussmuth $(2002,2003)$ has shown that herding behavior can give rise to a mode-locking mechanism, thus giving a natural explanation for financial market synchronization.

There are many different possible mode-locking models. Selover and Jensen (1999) attempted to model international business cycle synchronization using a simple mode-locking model based on sine waves to illustrate the mode-locking phenomenon. The model produced a number of results including the operation of the mode-locking mechanism with weak linkages, which could operate under conditions of extreme noise, time-varying parameters, and external shocks. Simulations showed how the mode-locking mechanism could work under extremely irregular conditions like those in business cycles. However, the Selover and Jensen (1999) model was too regular and used sine functions, hard to justify in economics. The present model from Selover, Jensen, and Kroll $(2003,2005)$ eliminates some of those issues.

In this model we assume the existence of two stock markets and a transmission channel between the two. If stock market $\mathrm{X}$ enters a period of growth, it transmits some of that growth to stock market $\mathrm{Y}$, providing a modest stimulus to market $\mathrm{Y}$, slightly shifting the frequency and phase of stock market Y's fluctuations. This shifting persistently forces the two stock markets to converge upon a compromise frequency and synchronize with each other, but with a lag or phase differential. (Note 3) The pair is now in a state of mode-lock. The two stock markets are thus flexibly synchronized together as long as the two financial systems are linked via some transmission channel, and they will stay in sync until some idiosyncratic country shock pushes them out of sync. When the country-specific shock weakens, the mode-lock phenomenon again pulls them back into synchronization.

In this illustration we use the nonlinear "van der Pol oscillator" to simulate the individual stock markets of the economy. We are not suggesting that the stock markets are van der Pol processes. We simply use the van der Pol oscillator to illustrate the mode-locking phenomenon. In this example the van der Pol oscillator is analogous to a stock market, and we use it to demonstrate how the mode-locking phenomenon works to bring about the synchronization of different stock markets with weak linkages. (Note 4) We chose the van der Pol oscillator because it is simple and well-known. The van der Pol oscillator is based on a nonlinear second order differential equation model. It will represent the deterministic component of fluctuations in a stock market. The use of this example comes from Selover, Jensen, and Kroll (2005).

The van der Pol oscillator consists of three terms:

$$
m x^{\prime \prime}(t)+r\left(x(t)^{2}-1\right) x^{\prime}(t)+k x(t)=0
$$


where $x=$ the stock market index growth rate in terms of percent per period

$m=$ the inertial term provides a tendency of the market to keep on growing

$r=$ the nonlinear damping term; ' $r$ ' determines the speed of adjustment

$k=$ the restoring force term; restores the market to equilibrium at $\mathrm{x}=0$

The first term is the inertial term, $m x^{\prime \prime}(t)$. This term ensures that the market will tend to continue to grow at its present rate until another force is introduced that changes that growth rate. The inertial term coefficient, $m$, is a measure of the tendency of a moving system to continue moving at its present rate.

The second term is the $r\left(x(t)^{2}-1\right) x^{\prime}(t)$ nonlinear damping term. The non-linear form of this term is special to the van der Pol equation, and represents a type of friction, corresponding to economic or financial adjustment costs. When $x$ is large, $(|x|>1)$, there is persistent damping. When $x$ is small, $(|x|<1), x$ is re-stimulated, re-energizing the system. This is similar to when a market, reaching the bottom of its cycle, is stimulated by investors taking advantage of low prices. The nonlinear damping term leads to a self-sustained oscillation (a limit cycle) with no need for outside forces. The parameter $r$ determines the strength and speed of adjustment.

The third term, $k x(t)$, is the restoring force that resists the motion that pushes $x$ too far from its equilibrium point at $\mathrm{x}=0$. This is a flexible, spring-like restoring force, which can be thought of as coming from the market reacting to over- or under-supply. A stock market cannot move too far out of equilibrium without financial forces forcing it back into equilibrium. The constant $k$ measures the strength of the restoring force. The oscillation is created from the interaction between the tendency for systems to remain in motion, $m x^{\prime \prime}(t)$, and the restoring force, $k x(t)$, that pushes the system back into equilibrium. The frequency of oscillation depends upon the restoring force constant $\mathrm{k}$ and the inertial parameter $m$ : (Note 5)

$$
f \approx \frac{\sqrt{k / m}}{2 \pi}
$$

Each national stock market, in isolation from other international stock markets, will tend, in a way similar to the van der Pol oscillator, to oscillate in an independent fashion according to its own inherent frequency. When we have two non-linear oscillators (stock markets) and link them via a transmission channel, we get mode-locking and a synchronization of the oscillations of one system to the other.

A van der Pol mode-locking system representing the coupling between two stock markets can be written as follows, with the linkages represented by the fourth terms in each equation:

$$
\begin{aligned}
& m_{x} x^{\prime \prime}(t)+r_{x}\left(x(t)^{2}-1.0\right) x^{\prime}(t)+k_{x} x(t)+h_{x} y(t)=0 \\
& m_{y} y^{\prime \prime}(t)+r_{y}\left(y(t)^{2}-1.0\right) y^{\prime}(t)+k_{y} x(t)+h_{y} x(t)=0
\end{aligned}
$$

where $h_{x}=$ the linear linkages of the Y market to the X market (Note 6)

$h_{y}=$ the linear linkages of the $\mathrm{X}$ market to the $\mathrm{Y}$ market.

The $h$ terms are the financial linkage parameters that couple the two markets together. These parameters need to be negative in order to force a positive impact from one oscillator to another. (Note 7) In reality these linkage channels may be due to linkages in trade in goods and services or in the transmission of information/expectations or in capital 
flows between the two financial systems. While the mode-locking model we explore here incorporates only two stock markets, the mode-locking mechanism can operate between many different stock markets.

\section{Simulations}

A numerical simulation from Selover et al $(2003,2005)$ illustrates how the mode-locking phenomenon works, even under conditions of noise like those seen in financial markets. The coupled van der Pol oscillator system in equations 3 and 4 is easy to simulate numerically. (Note 8) The first simulation, in Figure 1, shows the graphs of two unlinked oscillators (stock markets), without noise or exogenous shocks. The two "stock markets" have different starting values and different inherent frequencies. The fluctuations in the two unlinked stock markets do not synchronize, and the uncoupled processes move at different frequencies, and in and out of phase with each other.

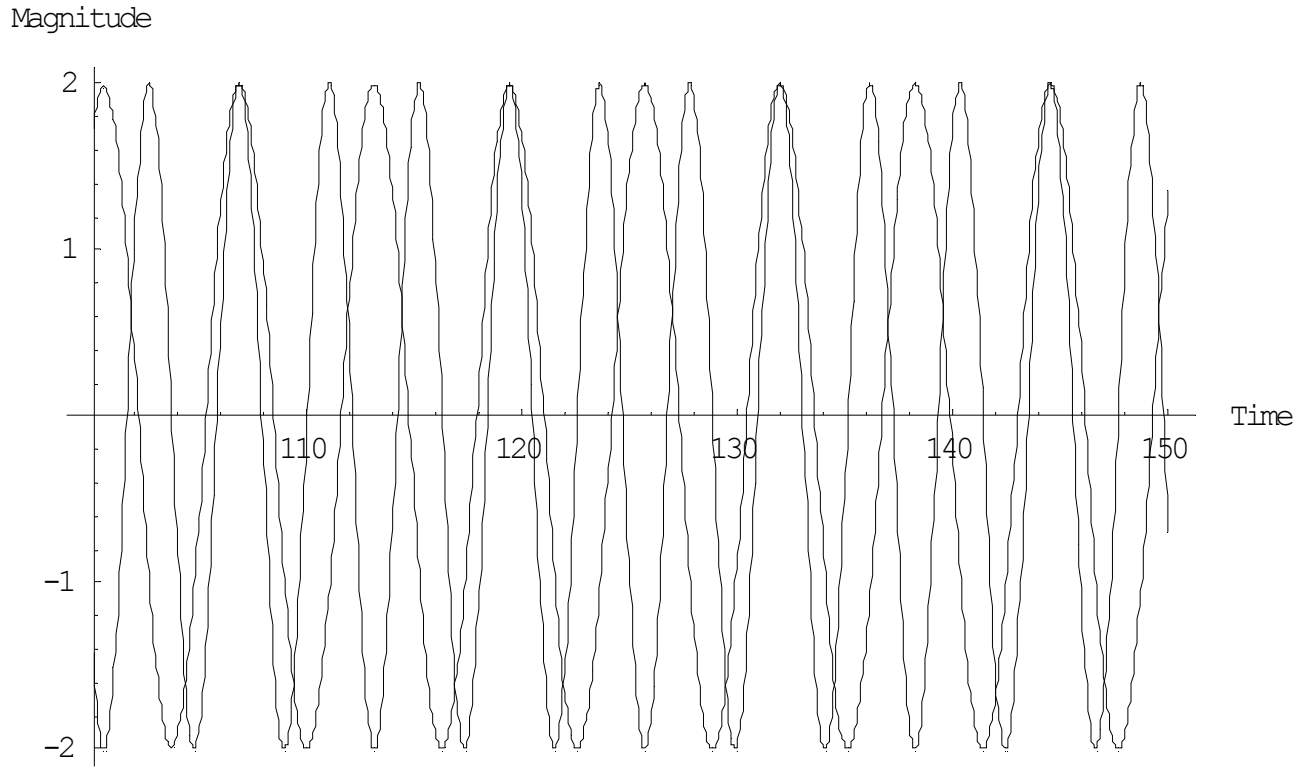

Figure 1. Simulation: two van der pol oscillators, no linkage, no mode-locking (from Selover, Jensen, and Kroll $(2003,2005))$

Figure 2 illustrates the case in which the linkage exceeds the mode-lock threshold value. The two oscillators have different starting values and different inherent frequencies. Nonetheless the two signals quickly mode-lock and synchronize with each other, with a small lag or phase difference. This synchronization occurs in spite of the two oscillators (stock markets) having different inherent frequencies. The presence of mode-locking is strikingly clear when the coupled processes move into sync in spite of the inherent frequency difference. Experimentation with different frequencies and linkage parameters illustrate the characteristics of the theoretical mode-locking model: stronger linkages bring about a quicker transition into synchronization and a smaller phase differential. Larger inherent frequency differences make mode-locking more difficult to attain and require stronger linkages to attain mode-lock. Larger inherent frequency differentials also mean larger phase differentials between the two mode-locking cycles. The market with the higher inherent frequency will tend to lead, and the market with the lower inherent frequency will tend to follow. These simulations clearly demonstrate the mode-locking phenomenon, and show how stock markets can synchronize with each other even with relatively weak linkages. (Note 9) 


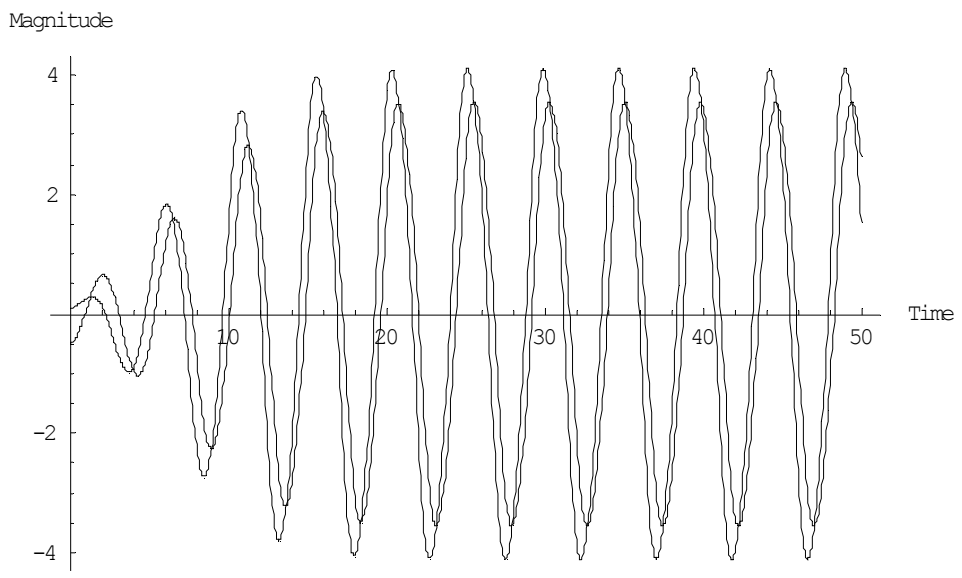

Figure 2. Simulation: two van der pol oscillators with linkage, mode-locking (from Selover, Jensen, and Kroll (2003, 2005))

The mode-locking phenomenon works even in the presence of a great deal of noise and random shocks. When independent random noises are added into the two markets, we can still achieve mode-lock. Figure 3 shows the results of simulations with two oscillators of different inherent frequencies in which the linkage is below the mode-locking threshold. Consequently, the oscillators do not mode-lock and do not synchronize. At the bottom of Figure 3 we see the spectral plots of the two oscillators, and they are each centered at different frequencies, 34 cycles per period and 39 cycles per period respectively.
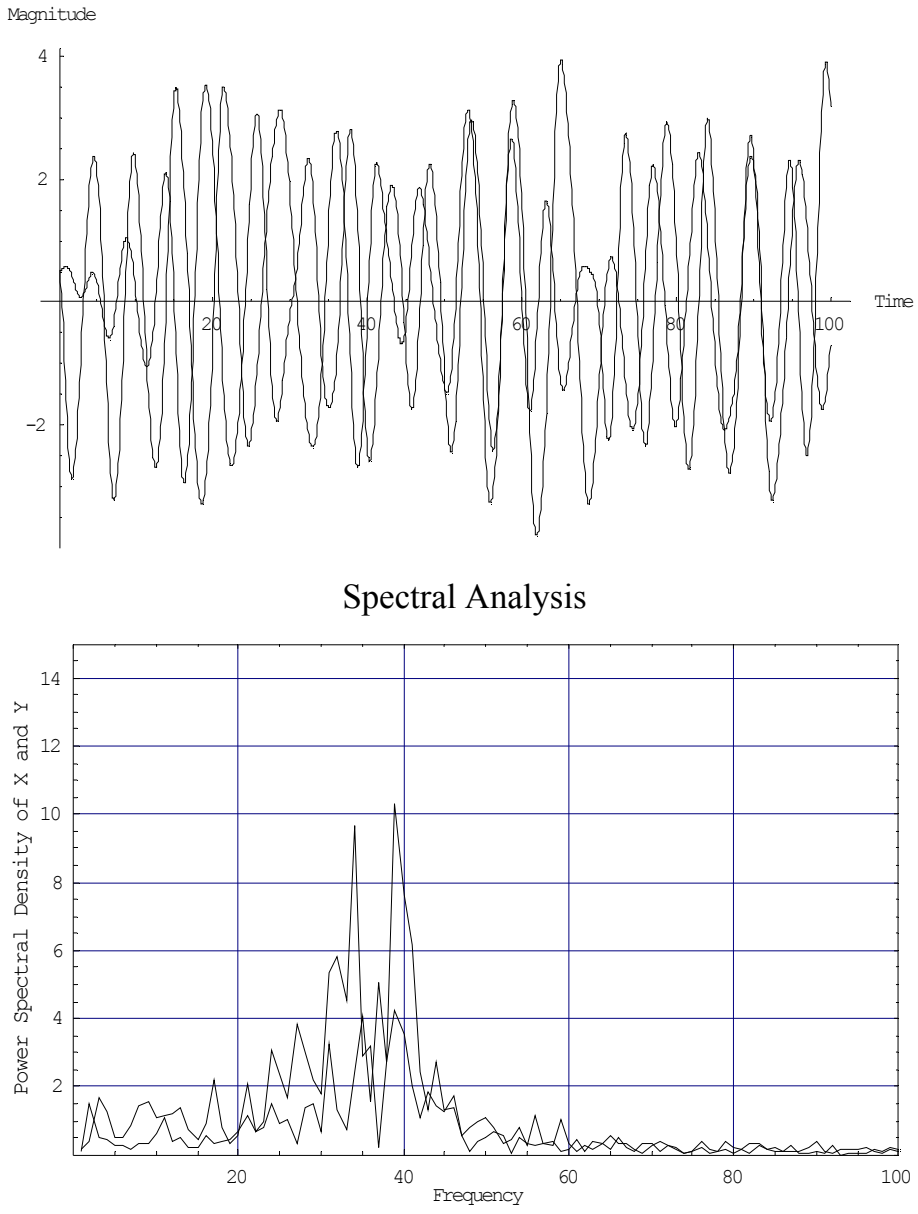

Figure 3. Simulation: two van der pol oscillators with noise, no linkage, no mode-locking (from Selover, Jensen, and Kroll $(2003,2005))$ 
Figure 4 shows the same noisy oscillators, but with a modest linkage between the two that exceeds the mode-locking threshold. The two oscillators dramatically mode-lock into synchronization and converge upon a compromise frequency. In the spectral plot at the bottom of Figure 4 we can see that the two spectral plots have converged on a compromise frequency. This simulation shows the ability of oscillator stock markets to mode-lock and synchronize even under conditions of extreme noise. This suggests that mode-locking is a plausible phenomenon which can force noisy oscillators, like financial markets, into synchronization.

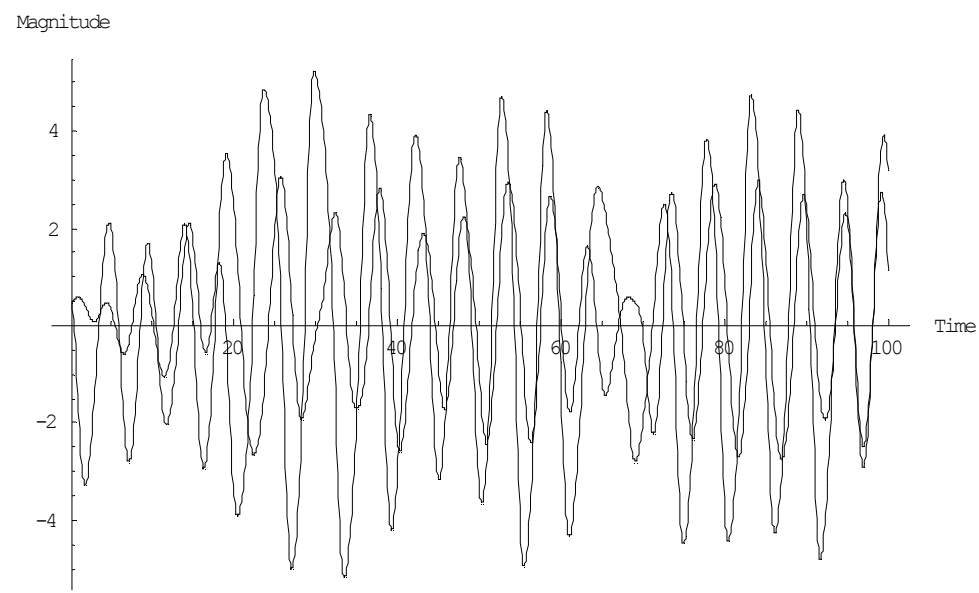

Spectral Analysis

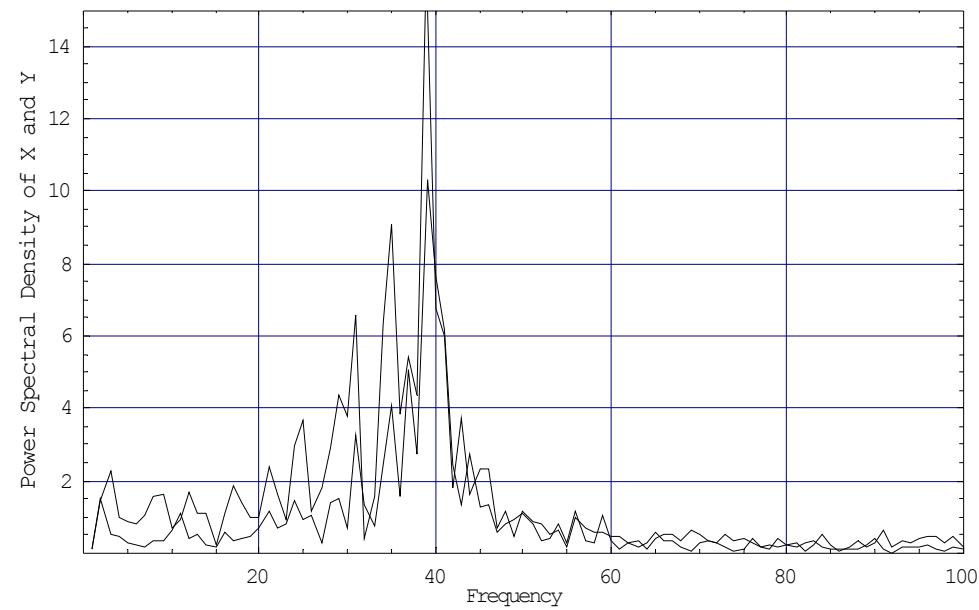

Figure 4. Simulation: two van der pol oscillators with noise with linkage, mode-locking (from Selover, Jensen, and Kroll $(2003,2005))$

\section{Methods of Empirical Analysis}

Here we present empirical evidence to support our claim of mode-locking between different stock markets in the global economy. This evidence includes the use of graphs, correlations, Granger causality tests, nonlinearity tests, spectral analysis, and cross-spectral analysis to illustrate the degree of co-movement and synchronization between different stock markets around the world. For this analysis we used the monthly growth rates of fourteen stock market indexes in the world economy over the period 1967.01 - 2010.02, see the data appendix.

There is no definitive test for mode-locking. The best tests that exist are based upon testing both the assumptions and the implications of the mode-locking model. Granger causality tests are used to test for linkages between stock markets. We cite Canova and De Nicolo $(1995)$ and Fama $(1981,1990)$ to provide evidence of deterministic relations between financial markets and the real economy. F-tests upon quadratic and cubic terms are used to test for nonlinearities. One of the implications of mode-locking between stock markets is that the mode-locking stock market fluctuations will tend to converge upon a "compromise frequency." Consequently, if different stock markets are mode-locking, their dominant frequencies should be equal, and this is examined through the use of spectral analysis 
and cross-spectral analysis. This is not a definitive test because other synchronizing mechanisms, such as common exogenous shocks, might also tend to produce equal dominant frequency fluctuations between different stock markets. In the future, perhaps statistical tests can be developed to distinguish mode-locking synchronization from other synchronization mechanisms.

\section{Empirical Results}

\subsection{Time Series Graphs}

Figures 5 and 6 display the logs of the monthly stock market indexes for fourteen national stock markets. What is remarkable about the graphs is the similarity of many of the graphs over the period $1967-2010$. Figure 5 presents the logged stock market indexes of the US, Germany, Spain, Canada, France, Japan, the UK, Italy, and Korea. Seven of the nine series are very similar, with two prominent common peaks in the years 2000-2001 and 2008. In particular, the graphs for the US and the UK are especially similar, and are also similar to those of Germany, France, and Italy, followed by those of Spain and Canada. The graphs of France and Germany are especially similar, as are the graphs of Italy and Spain. In this group of developed countries we see a high degree of synchronization among stock markets. We see a degree of synchronization between the US and Canada, but less synchronization with Mexico (see Figure 6). There are some pronounced differences between the graphs of Japan and Korea, but several of the turning points are synchronized. There are some similarities among the stock indexes in the Latin American markets, especially after 1995. However, they were quite different from each other during 1980 to 1995, especially during the period of the Latin American debt crisis when there was much volatility in Argentina and Brazil. In some cases there is synchronization between stock markets and in some cases there is not, thus mode-locking is not occurring between all stock markets.

US: Log Stock Market

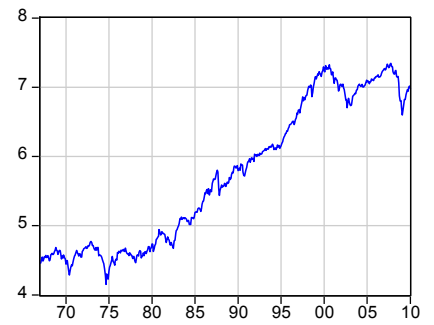

Canada: Log Stock Market

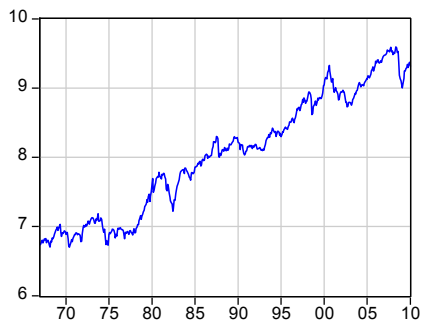

UK: Log Stock Market

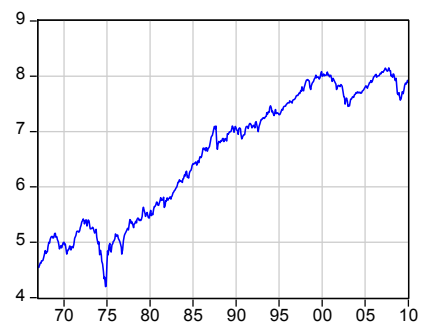

Germany: Log Stock Market

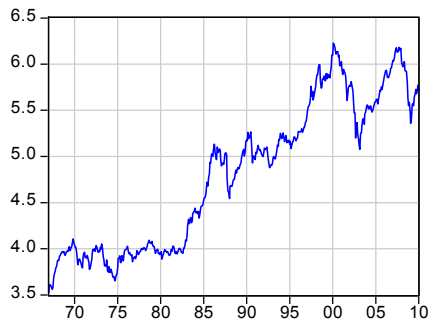

France: Log Stock Market

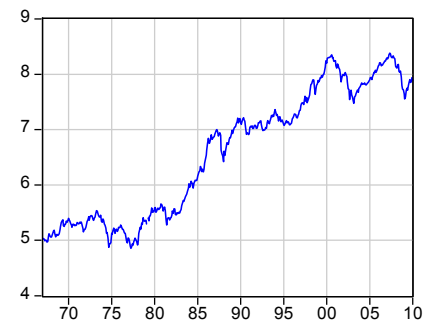

Italy: Log Stock Market

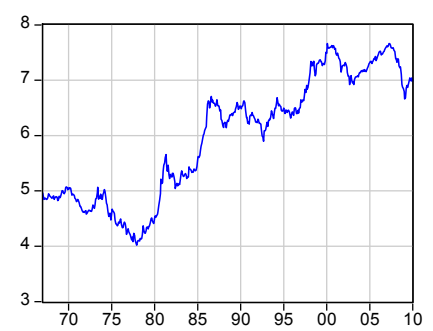

Spain: Log Stock Market

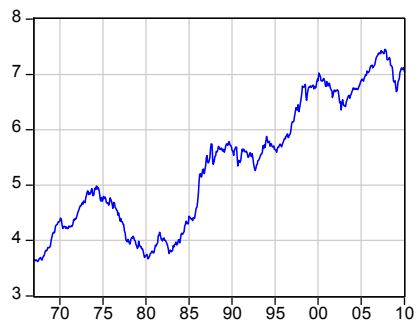

Japan: Log Stock Market

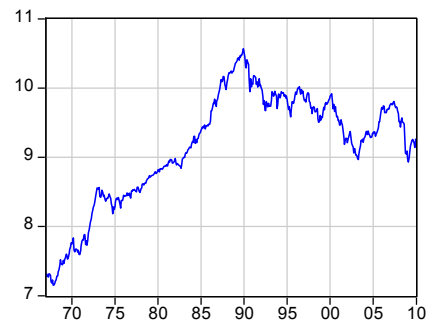

Korea: Log Stock Market

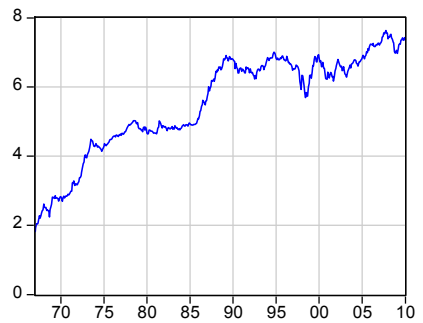

Figure 5. Log of stock market indexes: time series plots 
US: Log Stock Market

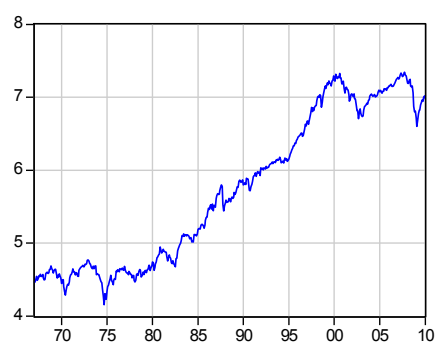

Mexico: Log Stock Market

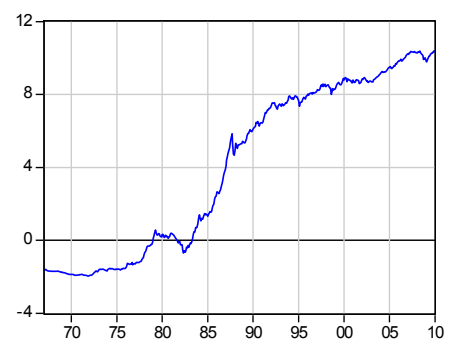

Argentina: Log Stock Market

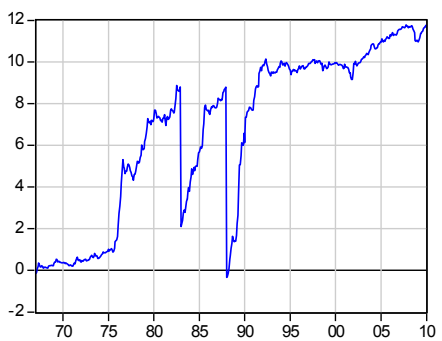

Brazil: Log Stock Market

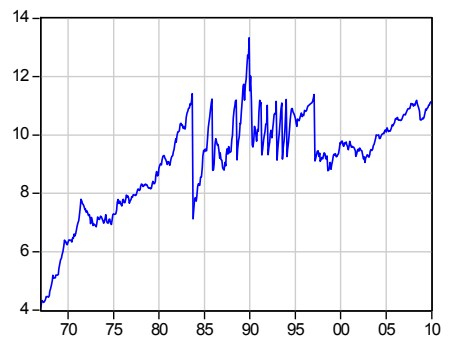

Colombia: Log Stock Market

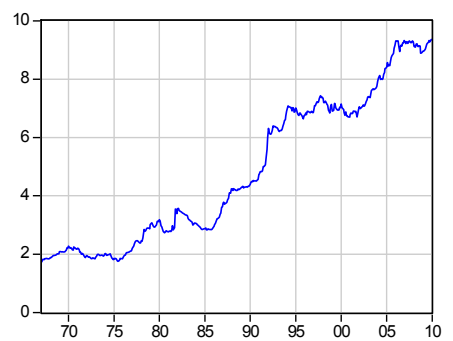

Venezuela: Log Stock Market

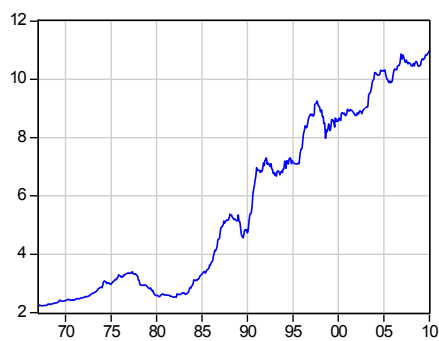

Figure 6. Log of stock market indexes: time series plots

\subsection{Stationarity Tests and Correlations}

We start the statistical analysis with tests of stationarity essential for the subsequent analysis. In Table 1 unit root tests (augmented Dickey-Fuller (ADF) tests) reveal all of the logged stock market indexes (except perhaps for Brazil) to be I(1) non-stationary. Therefore the detrending and subsequent analysis is done using the stationary first differences (the growth rates) of the logged stock indexes.

Table 1. Unit root tests

\section{Augmented Dickey-Fuller Tests}

Logs of Stock Market Indexes

$(1967.02-2010.01, \mathrm{n}=516)$

\begin{tabular}{lccccc}
\hline Variable & \multicolumn{2}{c}{$\mathrm{I}(0)$} & \multicolumn{2}{l}{$\mathrm{I}(1)$} & $\mathrm{I}(\mathrm{x})$ \\
\hline United States (US) & & & & & $\mathrm{I}(1)$ \\
\hline Canada & -0.51 & $(.89)$ & -21.35 & $(.00)^{* *}$ & $\mathrm{I}(1)$ \\
\hline Mexico & -0.69 & $(.00)$ & -20.35 & $(.00)^{* *}$ & $\mathrm{I}(1)$ \\
\hline France & -0.09 & $(.95)$ & -17.25 & $(.00)^{* *}$ & $\mathrm{I}(1)$ \\
\hline Germany & -0.85 & $(.80)$ & -19.67 & $(.00)^{* *}$ & $\mathrm{I}(1)$ \\
\hline Italy & -1.21 & $(.67)$ & -20.58 & $(.00)^{* *}$ & $\mathrm{I}(1)$ \\
\hline Spain & -0.70 & $(.84)$ & -20.48 & $(.00)^{* *}$ & $\mathrm{I}(1)$ \\
\hline United Kingdom (UK) & -0.80 & $(.82)$ & -18.78 & $(.00)^{* *}$ & $\mathrm{I}(1)$ \\
\hline Japan & -1.35 & $(.61)$ & -20.16 & $(.00)^{* *}$ & $\mathrm{I}(1)$ \\
\hline Korea & -2.47 & $(.12)$ & -21.42 & $(.00)^{* *}$ & $\mathrm{I}(1)$ \\
\hline Argentina & -2.68 & $(.07)$ & -20.87 & $(.00)^{* *}$ & $\mathrm{I}(1)$ \\
\hline Brazil & -1.74 & $(.41)$ & -22.26 & $(.00)^{* *}$ & $\mathrm{I}(0)$ \\
\hline Colombia & -3.22 & $(.02)^{*}$ & -24.70 & $(.00)^{* *}$ & $\mathrm{I}(1)$ \\
\hline Venezuela & 0.58 & $(.99)$ & -18.24 & $(.00)^{* *}$ & $\mathrm{I}(1)$ \\
\hline
\end{tabular}

$\mathrm{CV}(.05)=-2.87, \quad \mathrm{CV}(.01)=-3.44$. Significance levels: $*=.05, \quad * *=.01$. Number of augmentation terms selected by minimizing Schwarz criterion. 
The correlations between the monthly stock market growth rates, Table 2 , are relatively high, $(\mathrm{r}>.40)$, particularly among the US, Canada, the European countries, and Japan, and to a lesser extent, Mexico and Korea. These correlations indicate a great deal of synchronization among these stock markets. (Note 10) The South American countries, subject to many country-specific shocks, are markedly less correlated, both among themselves and with the other countries.

Table 2. Correlation matrix

Growth Rates of Stock Market Indexes

(1967.02 - 2010.01, monthly, $\mathrm{n}=512)$

\begin{tabular}{|c|c|c|c|c|c|c|c|c|c|c|c|c|c|}
\hline \multicolumn{14}{|c|}{ Correlations } \\
\hline & US & Canada & Mexico & France & Germany & Italy & Spain & UK & Japan & Korea & Argent & Brazil & Colombia \\
\hline US & 1.00 & & & & & & & & & & & & \\
\hline \multirow[t]{2}{*}{ Canada } & .77 & 1.00 & & & & & & & & & & & \\
\hline & $.00 * *$ & & & & & & & & & & & & \\
\hline \multirow[t]{2}{*}{ Mexico } & .37 & .35 & 1.00 & & & & & & & & & & \\
\hline & $.00 * *$ & $.00 * *$ & & & & & & & & & & & \\
\hline \multirow[t]{2}{*}{ France } & .58 & .55 & .33 & 1.00 & & & & & & & & & \\
\hline & $.00 * *$ & $.00 * *$ & $.00 * *$ & & & & & & & & & & \\
\hline \multirow[t]{2}{*}{ Germany } & .56 & .50 & .37 & .68 & 1.00 & & & & & & & & \\
\hline & $.00 * *$ & $.00 * *$ & $.00 * *$ & $.00 * *$ & & & & & & & & & \\
\hline \multirow[t]{2}{*}{ Italy } & .38 & .42 & .24 & .57 & .53 & 1.00 & & & & & & & \\
\hline & $.00 * *$ & $.00 * *$ & $.00 * *$ & $.00 * *$ & $.00 * *$ & & & & & & & & \\
\hline \multirow[t]{2}{*}{ Spain } & .47 & .42 & .38 & .55 & .57 & .52 & 1.00 & & & & & & \\
\hline & $.00 * *$ & $.00 * *$ & $.00 * *$ & $.00 * *$ & $.00 * *$ & $.00 * *$ & & & & & & & \\
\hline \multirow[t]{2}{*}{ UK } & .61 & .57 & .29 & .56 & .51 & .45 & .45 & 1.00 & & & & & \\
\hline & $.00 * *$ & $.00 * *$ & $.00 * *$ & $.00 * *$ & $.00 * *$ & $.00^{* *}$ & $.00^{* *}$ & & & & & & \\
\hline \multirow[t]{2}{*}{ Japan } & .42 & .41 & .26 & .41 & .41 & .36 & .42 & .37 & 1.00 & & & & \\
\hline & $.00 * *$ & $.00 * *$ & $.00 * *$ & $.00 * *$ & $.00 * *$ & $.00 * *$ & $.00 * *$ & $.00 * *$ & & & & & \\
\hline \multirow[t]{2}{*}{ Korea } & .26 & .28 & .23 & .21 & .24 & .17 & .27 & .26 & .36 & 1.00 & & & \\
\hline & $.00 * *$ & $.00 * *$ & $.00 * *$ & $.00 * *$ & $.00 * *$ & $.00 * *$ & $.00^{* *}$ & $.00 * *$ & $.00^{* *}$ & & & & \\
\hline \multirow[t]{2}{*}{ Argentina } & .01 & .06 & -.04 & .10 & .10 & .02 & -.01 & -.01 & -.02 & -.03 & 1.00 & & \\
\hline & .87 & .15 & .32 & $.02 *$ & $.02 *$ & .61 & .85 & .79 & .66 & .52 & & & \\
\hline \multirow[t]{2}{*}{ Brazil } & .14 & .16 & .05 & .08 & .03 & .06 & .04 & .12 & .12 & .10 & -.04 & 1.00 & \\
\hline & $.00 * *$ & $.00 * *$ & .31 & .08 & .49 & .18 & .33 & $.01 * *$ & $.00 * *$ & $.03 *$ & .33 & & \\
\hline \multirow[t]{2}{*}{ Colombia } & .14 & .15 & .11 & .06 & .11 & .09 & .12 & .11 & .09 & .14 & .05 & .00 & 1.00 \\
\hline & $.00 * *$ & $.00 * *$ & $.02 *$ & .15 & $.01 * *$ & .05 & $.00 * *$ & $.01 *$ & $.03 *$ & $.00 * *$ & .29 & .95 & \\
\hline \multirow[t]{2}{*}{ Venezuela } & .12 & .15 & .16 & .02 & .00 & .03 & .09 & .04 & .07 & .06 & -.01 & .02 & .18 \\
\hline & $.00 * *$ & $.00 * *$ & $.00 * *$ & .61 & .97 & .52 & $.04 *$ & .43 & .13 & .19 & .77 & .59 & $.00 * *$ \\
\hline
\end{tabular}

Correlation coefficient above, p-value below. $*=$ sig at .05 level, $* *=$ sig at .01 level.

\subsection{Granger Causality Tests}

Given this evidence of synchronization, we might ask, is this synchronization due to one market "driving" the others, or is there evidence of shocks being transmitted from one national stock market to another? In Table 3, Granger causality tests (F-tests) (using two lags) between the different national stock market growth rates reveal a relatively modest amount of Granger causality from one market to another. The national stock markets along the left column of the table represent the independent variables or potential "causal" markets, while the markets across the top of each column are the dependent variables, or markets being "caused." The US market does appear to have moderate Granger causal effects on many of the other markets, a finding similar to those of other researchers. Perhaps echoing the effects of the US market, the Canadian and Mexican markets appear to Granger cause several other markets around the world. Other relations appear to be plausible, such as Granger causal effects of the French and Spanish markets showing significant effects upon the Italian stock market. In some cases there appear to be anomalous findings of causality, such as the Argentine stock market "Granger causing" the French stock market. However, in general, we find little other evidence of strong transmission effects from one market to another. Transmission effects 
may be present, but the transmission is possibly conditional, not easily captured by bivariate tests of Granger causality. These results are exactly what we expect to find in the mode-locking case in which there are relatively weak linkages between markets which give rise to a synchronization of these stock markets. Mode-locking does not imply a cointegration relationship, so cointegration tests are not reported here. (Note 11)

Table 3. Granger causality test matrix (F-tests and p-values)

Growth Rates of Stock Market Indexes

$(1967.02-2010.01$, monthly, $\mathrm{n}=512$, lags $=2)$

\begin{tabular}{|c|c|c|c|c|c|c|c|c|c|c|c|c|c|c|}
\hline Dependent $\rightarrow$ & US & Canada & Mexico & France & Germany & Italy & Spain & UK & Japan & Korea & Argent & Brazil & Colombia & Venezuela \\
\hline \multicolumn{15}{|l|}{ Independ $\downarrow$} \\
\hline \multirow[t]{2}{*}{ US } & & 3.16 & 3.79 & 2.25 & 7.05 & 5.12 & 3.07 & 0.53 & 4.24 & 3.72 & 2.13 & 0.12 & 5.43 & 0.05 \\
\hline & & $.04 *$ & $.02 *$ & .11 & $.001 * *$ & $.01^{* *}$ & $.05^{*}$ & .59 & $.02 *$ & $.02 *$ & .12 & .89 & $.005 * *$ & .96 \\
\hline \multirow[t]{2}{*}{ Canada } & 0.13 & & 3.36 & 1.25 & 4.49 & 3.05 & 0.93 & 0.31 & 3.52 & 2.94 & 0.93 & 0.05 & 1.37 & 0.01 \\
\hline & .88 & & $.04 *$ & .29 & $.01 *$ & $.05^{*}$ & .39 & .74 & $.03 *$ & .05 & .40 & .95 & .26 & .99 \\
\hline \multirow[t]{2}{*}{ Mexico } & 0.19 & 0.50 & & 1.43 & 2.28 & 3.12 & 0.70 & 0.72 & 3.48 & 2.12 & 11.97 & 1.59 & 3.42 & 0.58 \\
\hline & .83 & .61 & & .24 & .10 & $.04 *$ & .50 & .49 & $.03 *$ & .12 & $.00^{* *}$ & .20 & $.03 *$ & .56 \\
\hline \multirow[t]{2}{*}{ France } & 0.25 & 0.55 & 2.07 & & 1.08 & 3.66 & 1.06 & 0.94 & 2.59 & 1.17 & 1.14 & 0.82 & 4.36 & 0.23 \\
\hline & .78 & .58 & .13 & & .34 & $.03 *$ & .35 & .39 & .08 & .31 & .32 & .44 & $.01 *$ & .80 \\
\hline \multirow[t]{2}{*}{ Germany } & 0.04 & 0.59 & 0.13 & 1.15 & & 0.55 & 0.32 & 1.07 & 0.21 & 2.43 & 2.16 & 0.19 & 1.53 & 0.25 \\
\hline & .96 & .55 & .88 & .32 & & .57 & .73 & .34 & .81 & .09 & .12 & .83 & .22 & .78 \\
\hline \multirow[t]{2}{*}{ Italy } & 1.17 & 0.68 & 0.01 & 0.48 & 1.00 & & 0.32 & 0.21 & 2.08 & 1.61 & 1.29 & 0.65 & 0.13 & 0.82 \\
\hline & .31 & .51 & .99 & .62 & .37 & & .72 & .81 & .13 & .20 & .27 & .52 & .88 & .44 \\
\hline \multirow[t]{2}{*}{ Spain } & 4.79 & 3.93 & 0.89 & 2.51 & 1.67 & 3.18 & & 0.98 & 2.17 & 2.26 & 0.10 & 0.55 & 0.79 & 0.47 \\
\hline & $.01^{* *}$ & $.02 *$ & .41 & .08 & .19 & $.04 *$ & & .38 & .12 & .11 & .90 & .58 & .46 & .62 \\
\hline \multirow[t]{2}{*}{ UK } & 1.31 & 1.04 & 2.41 & 0.35 & 2.48 & 1.91 & 0.03 & & 3.83 & 4.98 & 2.61 & 0.41 & 0.10 & 0.48 \\
\hline & .27 & .35 & .09 & .70 & .08 & .15 & .97 & & $.02 *$ & $.01 * *$ & .07 & .66 & .91 & .62 \\
\hline \multirow[t]{2}{*}{ Japan } & 1.01 & 2.54 & 0.01 & 0.43 & 1.83 & 0.59 & 0.47 & 0.34 & & 0.03 & 0.46 & 0.74 & 1.79 & 0.13 \\
\hline & .36 & .08 & .99 & .65 & .16 & .55 & .63 & .71 & & .97 & .63 & .48 & .17 & .88 \\
\hline \multirow[t]{2}{*}{ Korea } & 0.31 & 2.43 & 0.96 & 2.48 & 0.70 & 0.74 & 2.66 & 1.10 & 4.94 & & 0.91 & 1.70 & 0.99 & 0.63 \\
\hline & .74 & .09 & .38 & .08 & .50 & .48 & .07 & .33 & $.01 * *$ & & .40 & .18 & .37 & .53 \\
\hline \multirow[t]{2}{*}{ Argentina } & 0.41 & 0.92 & 7.72 & 4.83 & 3.34 & 0.66 & 1.50 & 0.22 & 0.39 & 0.44 & & 1.79 & 0.46 & 0.42 \\
\hline & .67 & .40 & $.00^{* *}$ & $.008^{* *}$ & $.04 *$ & .52 & .22 & .80 & .68 & .64 & & .17 & .63 & .66 \\
\hline \multirow[t]{2}{*}{ Brazil } & 1.13 & 0.65 & 1.07 & 0.44 & 0.34 & 0.34 & 0.22 & 0.26 & 1.12 & 4.20 & 0.89 & & 0.08 & 0.26 \\
\hline & .32 & .53 & .35 & .64 & .72 & .71 & .80 & .77 & .33 & $.02 *$ & .41 & & .92 & .77 \\
\hline \multirow[t]{2}{*}{ Colombia } & 0.35 & 1.05 & 0.82 & 0.22 & 0.66 & 0.53 & 0.01 & 0.05 & 0.36 & 1.67 & 0.87 & 0.57 & & 1.64 \\
\hline & .71 & .35 & .44 & .80 & .52 & .59 & .99 & .95 & .70 & .19 & .42 & .57 & & .19 \\
\hline \multirow[t]{2}{*}{ Venezuela } & 0.12 & 0.05 & 0.02 & 0.54 & 0.22 & 0.46 & 0.86 & 0.12 & 1.09 & 0.39 & 0.16 & 1.07 & 1.12 & \\
\hline & .89 & .95 & .98 & .58 & .80 & .63 & .42 & .89 & .34 & .67 & .85 & .34 & .33 & \\
\hline
\end{tabular}

F-statistics above, p-values below. $*=$ sig at .05 level, $* *=$ sig at .01 level.

\subsection{Nonlinearity Test Results}

One of the necessary conditions for mode-locking to occur is the existence of nonlinearities, either in the markets themselves or in the linkages. Scheinkman and LeBaron (1989) and others have found that stock market returns typically exhibit nonlinearities in their generating processes. Using a simple test for nonlinearities in the relationships between stock markets, nonlinearities were found in the stock market returns for some of the markets.

We used a simple test for quadratic and cubic nonlinearities in the domestic stock markets or in their linkages with other markets. Such nonlinearities can give rise to mode-locking and the consequent synchronization of the markets. We created a simple test for nonlinearities between two markets, $\mathrm{X}$ and $\mathrm{Y}$ by using an F-test upon the coefficients of some lagged nonlinear terms. We include both quadratic and cubic lagged terms so that we can allow for both symmetric and asymmetric effects. A rejection of the null hypothesis indicates the existence of significant nonlinear effects. Table 4 reports the results of tests for possible quadratic and cubic dependence in the stock returns data. (Note 12) 


$$
\begin{gathered}
y_{t}=\beta_{1}+\beta_{2} y_{t-1}+\beta_{3} y_{t-2}+\beta_{4} x_{t-1}+\beta_{5} x_{t-2}+ \\
+\beta_{6} y_{t-1}^{2}+\beta_{7} y_{t-1}^{3}+\beta_{8} x_{t-1}^{2}+\beta_{9} x_{t-1}^{3}+\beta_{10} y_{t-2}^{2}+\beta_{11} y_{t-2}^{3}+\beta_{12} x_{t-2}^{2}+\beta_{13} x_{t-2}^{3} \\
H_{0}: \beta_{i}=0 \forall i=6, \cdots, 13 \text { and } H_{A}: \beta_{i} \neq 0, \text { for some } i=6, \cdots, 13
\end{gathered}
$$

Several of the nonlinearities in the relationships were found to be statistically significant, and we concluded that the stock market returns in some of the markets exhibit nonlinearities in their generating or linkage processes.

Table 4. Nonlinearity tests (F-tests and p-values)

Test of Growth Rates of Stock Market Index Quadratic and Cubic Terms

$$
(1967.02-2010.01 \text {, monthly, } \mathrm{n}=512 \text {, lags=2) }
$$

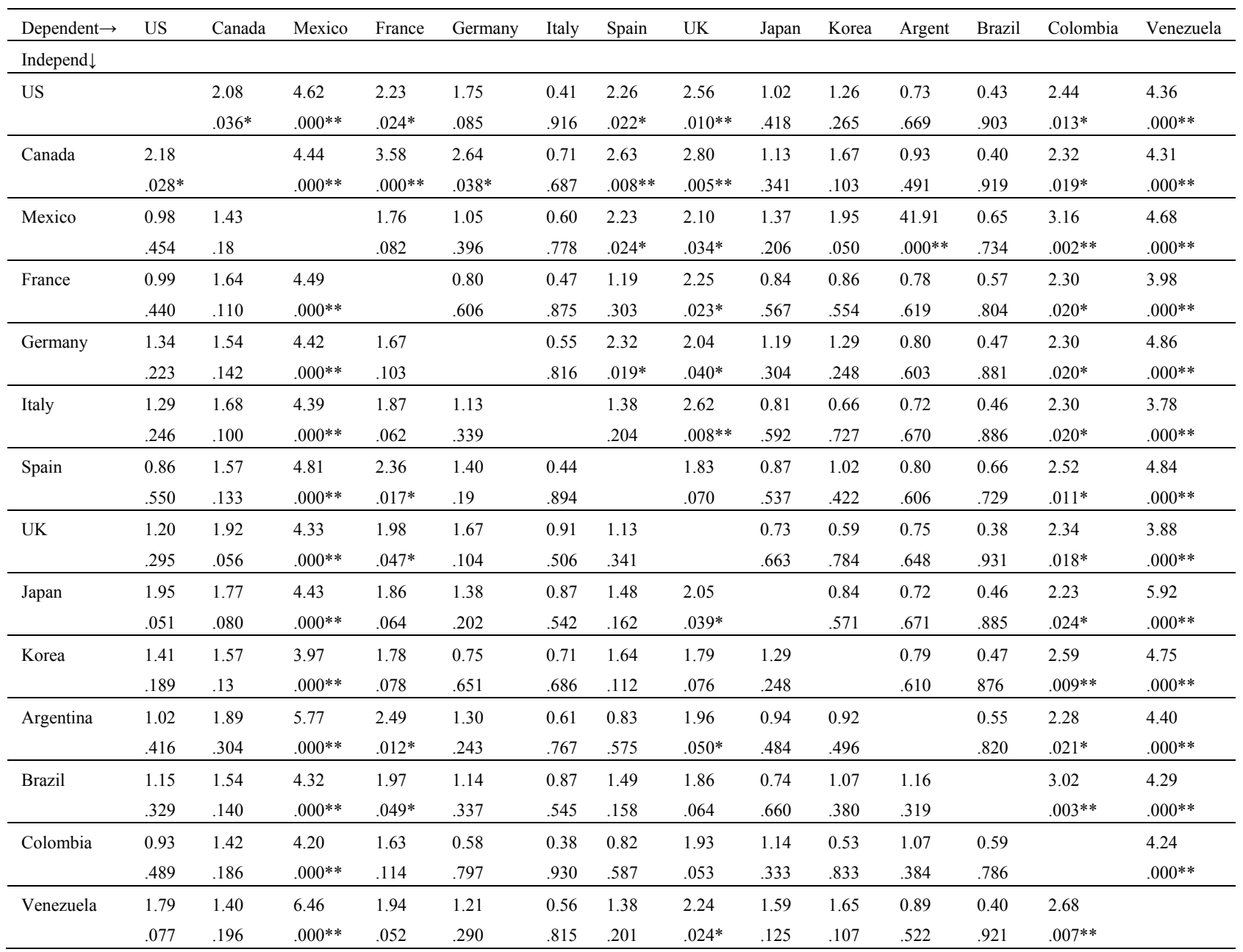

F-statistics above, p-values below. $*=$ sig at .05 level, $* *=$ sig at .01 level.

\subsection{The Spectral Shapes of the Growth Rates of the National Stock Market Indexes}

One of the implications of mode-locking is that the different oscillators (stock markets) should converge on the same compromise frequency, even if their inherent frequencies in isolation would fluctuate at different frequencies. Thus, if the various stock market fluctuations are mode-locking, we should observe a convergence on the dominant frequency as reflected in their frequency spectra. We observe just such a convergence in several of the country pairs.

Figures 7 and 8 show the log spectra of the monthly growth rates of twelve of the national stock market indexes. (Note 13) In each graph the horizontal axis represents frequency, ranging from zero frequency (a time trend) up to a frequency of 1.0 (one) cycle per year, the annual or seasonal frequency. (Note 14) Thus frequencies of 0.33 or 0.25 cycles per year would represent business cycles of three years or four years in length respectively. The vertical axis represents the magnitude of the log spectrum, giving the relative importance of each frequency component in the stock market index growth rate. $95 \%$ confidence intervals have been constructed around the log spectra using the 
asymptotic distribution. (Note 15)
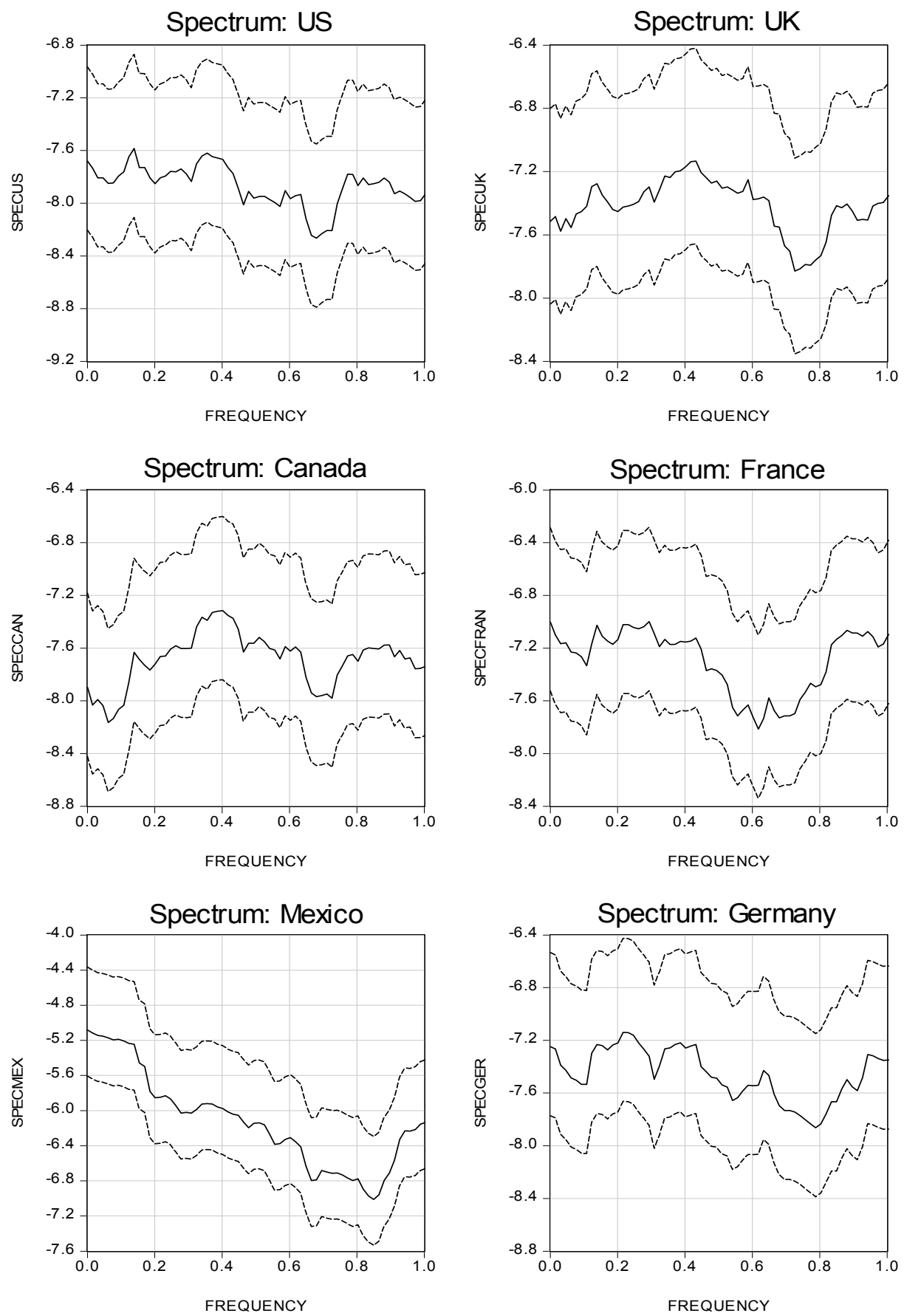

Figure 7. Spectra of stock market growth rates 

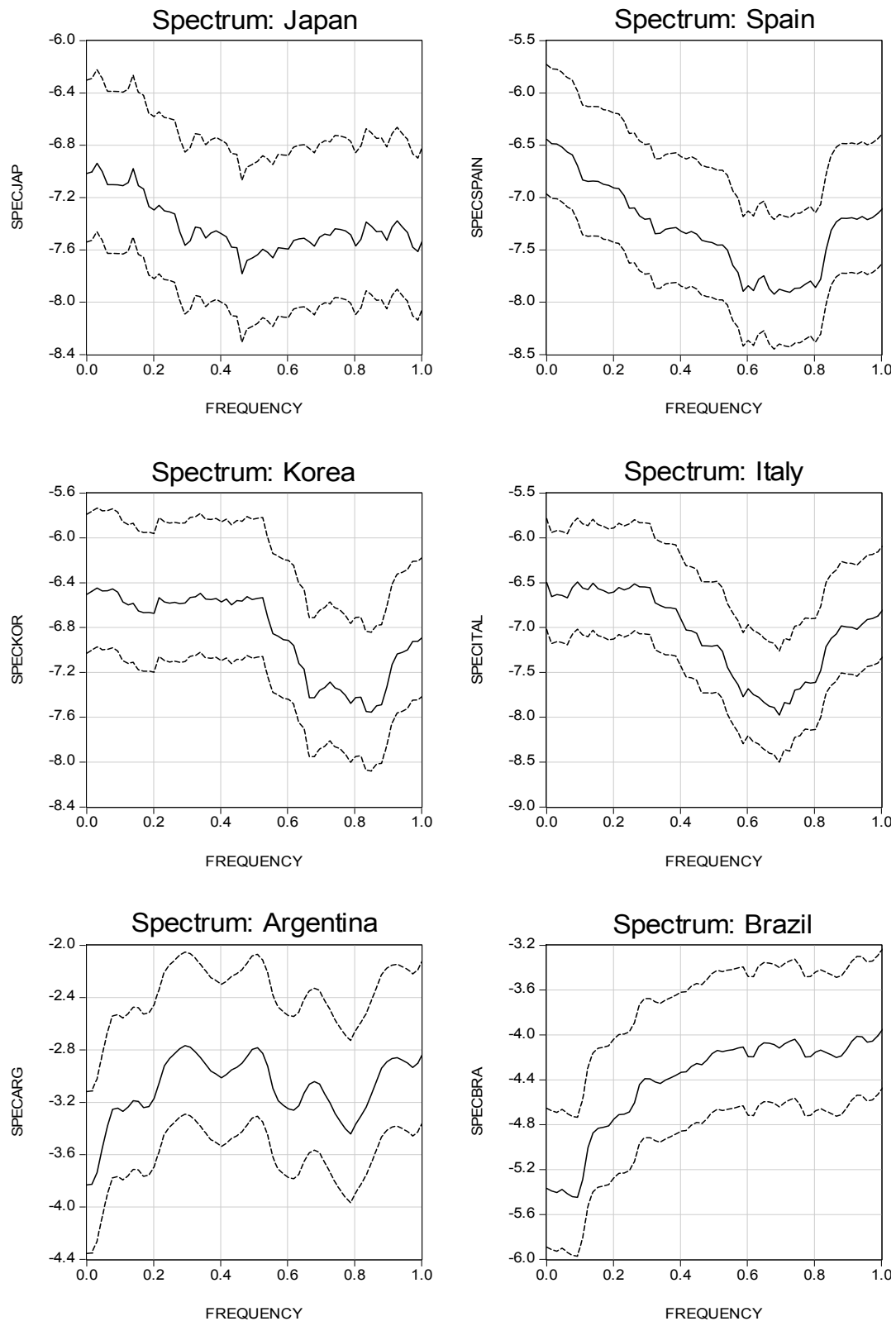

Figure 8 . Spectra of stock market growth rates

In the spectral graphs we look first for the presence of a spike or dominant frequency (different from zero or one) for each market which would indicate the presence of some periodic behavior in stock market growth. Second, we are looking for similarities in the spectral shapes and dominant frequencies for the different stock markets. For example, we see similar spectral shapes between the stock markets in the US and Canada which peak at the frequency of about 0.4 (fluctuations of about 2.5 years in length). This evidence is supportive of the existence of mode-locking between the US and Canada. On the other hand, the spectral shape of Mexico (at the bottom) is quite different from the US and Canadian spectral shapes, without a common peak, suggesting that the Mexican market does not mode-lock with the US stock market. The spectral shapes of the UK, France, Germany, and Italy, and to a certain extent Spain, are similar with at least one local peak at around 0.4 (2.5 year cycles), suggesting a certain level of mode-locking with each other and with the US and Canada.

The spectral shapes of Japan and Korea (Figure 8) are surprisingly different, perhaps reflecting the very different directions of economic and financial policy. The spectral shapes of Argentina and Brazil are also very different, reflecting the very different economic and financial performance and problems of those two countries and a lack of mode-locking. 


\subsection{Cross-Spectral Analysis}

Figures 9, 10, and 11 report the results of cross-spectral analysis for selected pairs of countries. Each graph plots the "coherence" for a pair of countries over the frequency spectrum. For example, in the graph of coherence between the monthly stock price index growth rates of the US and Canada, the horizontal axis represents the frequency of the stock price growth rate fluctuations in terms of cycles per year, and the vertical axis represents the coherence between the two stock market growth rates at each different frequency. Coherence is analogous to a squared correlation coefficient $\left(\mathrm{R}^{2}\right)$ between the two stock index growth rates for each different frequency. Coherence can thus range from 0 to a perfect coherence of 1.0. A computed critical value for the estimated coherences is 0.532 . Thus any coherence greater than 0.532 is considered statistically significant. (Note 16)

The coherence between the US and Canada (Figure 9) is relatively high (0.92) with local peaks at the frequencies of $0.4,0.5$, and 0.8 . This is evidence in support of mode-locking between the US and Canadian stock markets at these frequencies. We disregard the high coherence at the frequency of 1.0 because this is likely a spurious coherence due to seasonality.
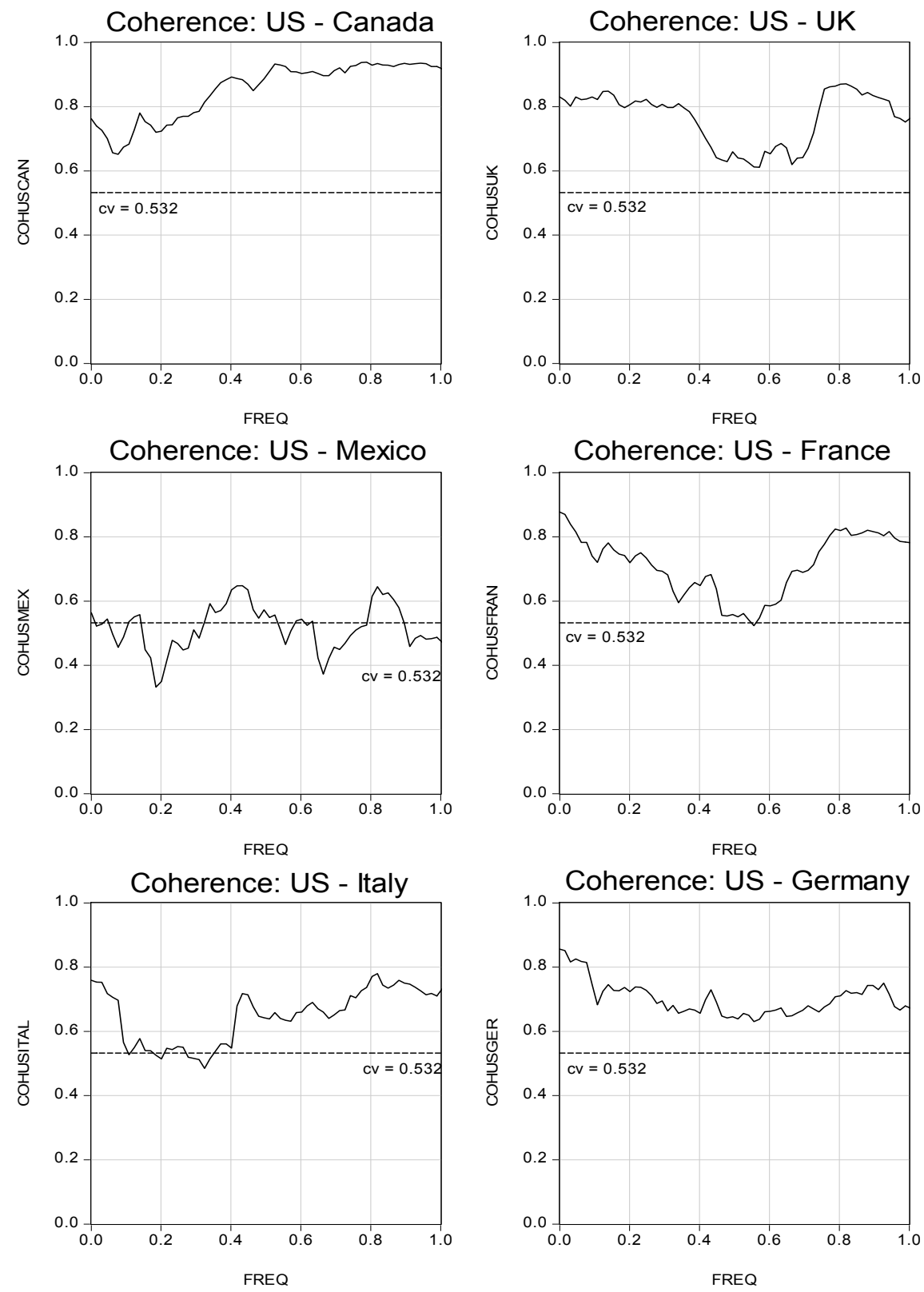

Figure 9. Cross-spectra coherences of stock market growth rate pairs 
Between the US and the UK there appears to be a high coherence at frequencies from 0 to 0.4 and at 0.8 with coherence values above 0.80 , indicating possible mode-locking. Between the US and Mexico there are peaks in coherence between the frequencies of 0.4 and 0.8 , but at a much lower coherence of 0.64 . We also see potential mode-locking between the US, France, Germany, and Italy, but little evidence of mode-locking between the US, Korea, and Latin America, Figure 10. Surprisingly the coherence between the Japanese and Korean stock markets is not very high (below 0.70) at most frequencies, but is still significant.
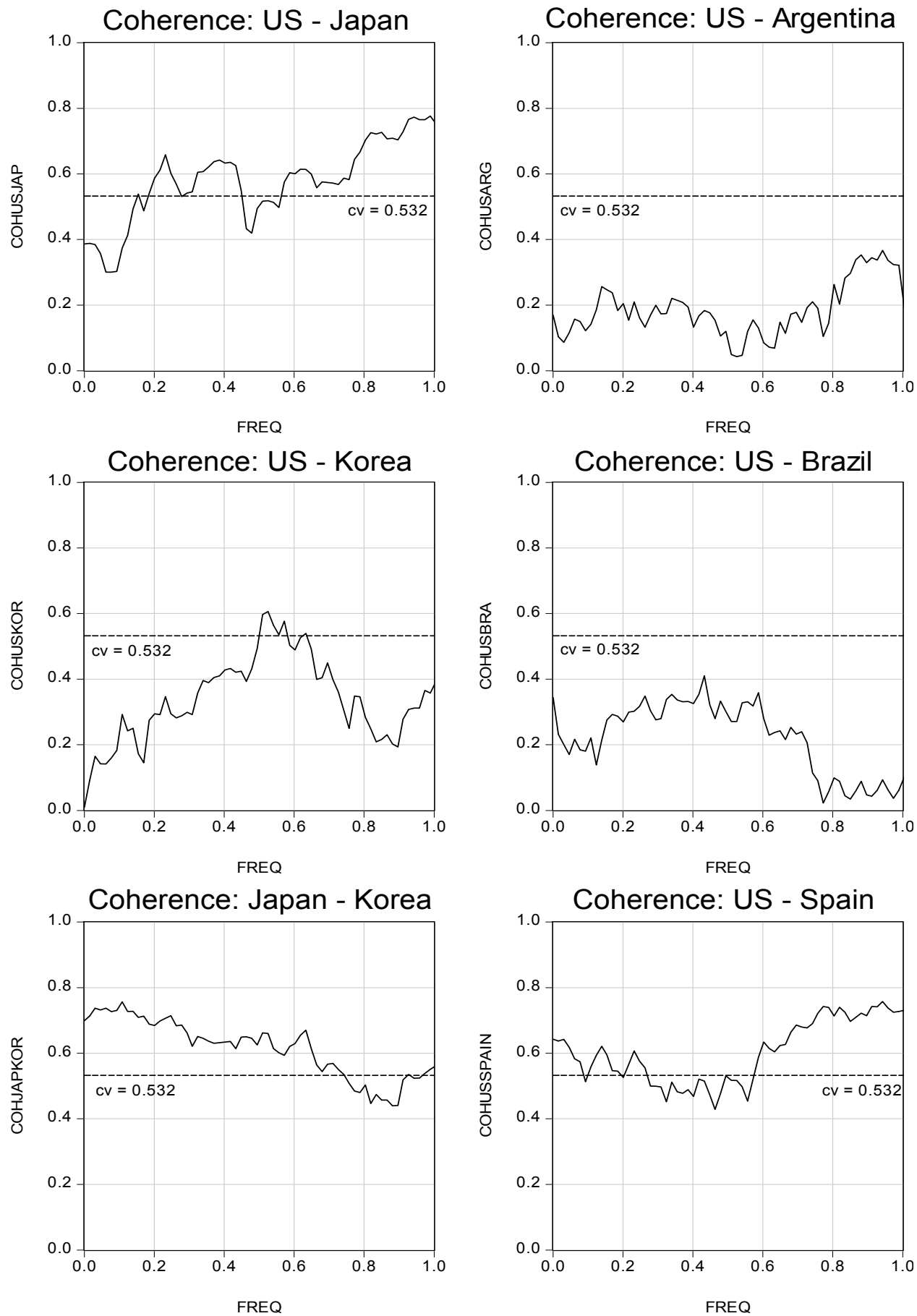

Figure 10. Cross-spectra coherences of stock market growth rate pairs

In Figure 11, we see the cross-spectra coherences between the UK and France, Italy, Germany, and Spain. For all four of these country pairs, the coherence is maximized around the frequencies of 0.8 to 1.0 , with the UK-Germany 
coherence maximizing at a frequency of about 0.85 and a coherence of about 0.75 . The France-Germany cross-spectra appears to be a relatively high coherence $(\approx 0.75)$ and is relatively flat, suggesting strong correlations at several frequencies, such as $0.12,0.25,0.45$, and 0.65 . Thus there appears to be some measure of mode-locking among the European countries. Figure 12 displays some of the cross-spectra phase relationships. The US stock market leads the Canadian stock market some at business cycle frequencies. However, for certain frequencies the UK market slightly leads the US market. The US market leads the Mexican market by a substantial amount at most business cycle frequencies.
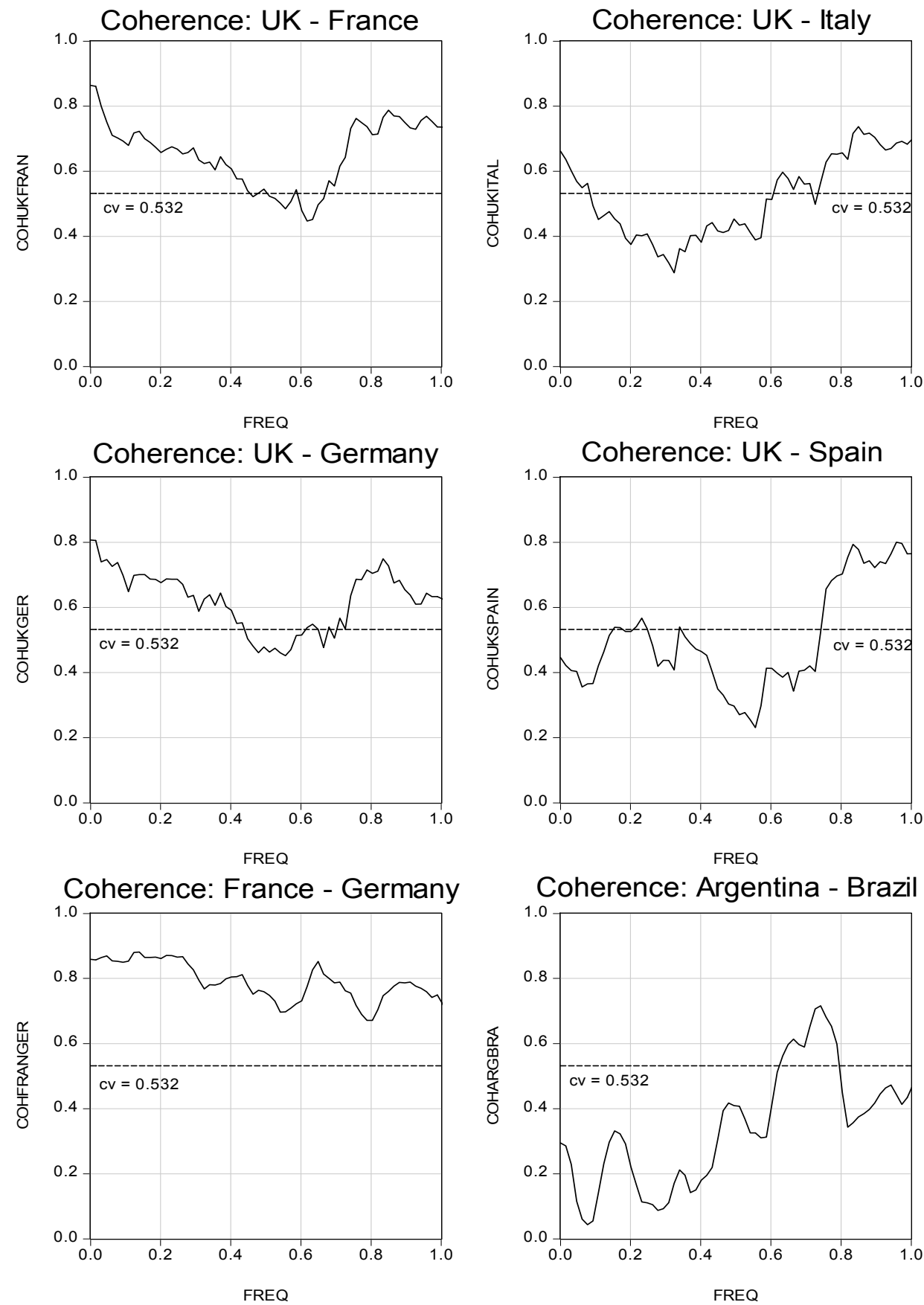

Figure 11. Cross-spectra coherences of stock market growth rate pairs 

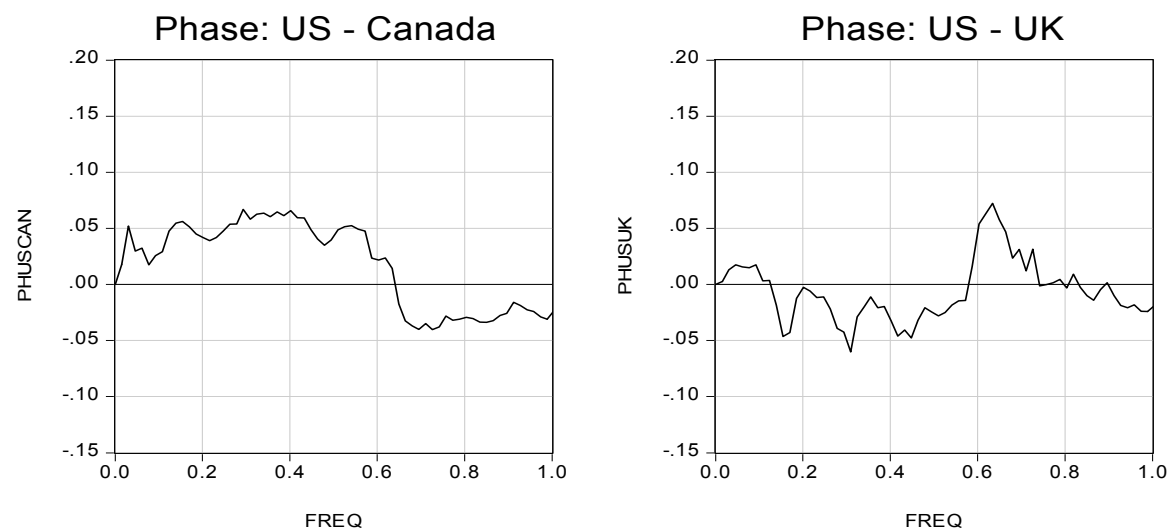

Phase: US - Mexico
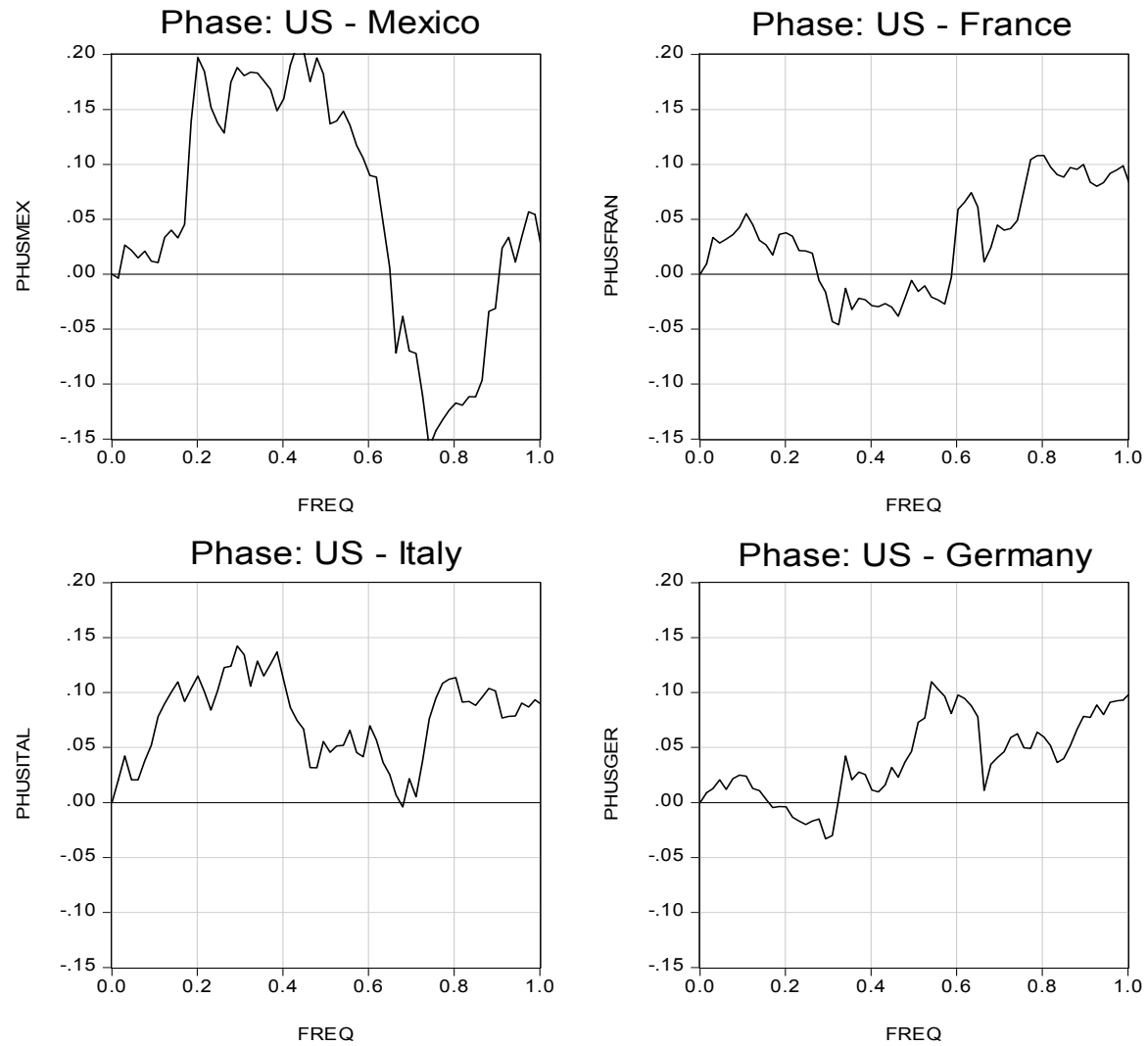

Figure 12. Cross-spectra phase relationships of stock market growth rate pairs

The similarities in spectra and the strong cross-spectra coherences are supportive of the hypothesis of mode-locking between the stock markets. We have thus established the possibility of mode-locking and have shown that the data are moderately consistent with the mode-locking hypothesis of shock market synchronization.

\section{Conclusions}

One of the stylized facts of international stock markets is that the fluctuations of the major stock markets tend to synchronize with each other. However the trade, financial, and expectational linkages between such markets are multi-channeled, indirect, variable, weak, and subject to large random shocks. The question we address here is, why do the fluctuations of different financial markets tend to synchronize even if the linkages between them are weak?

In this paper we propose that international stock market synchronization arises through a "mode-locking" phenomenon between the stock price fluctuations of the different stock markets, operating through transmission channels, including mutual trade in goods and services, capital flows, possible expectational or contagion effects, the similarity of industrial structures, or investment fund packaging effects. Sussmuth (2002) has suggested that mode-locking and co-movement can arise from herd behavior, like that observed in financial markets. This mode-locking phenomenon helps explain the periodicity, the persistence, and the timing of the synchronization 
between international stock markets. More importantly, it explains why the synchronization takes place even if the linkages are weak. The mode-locking model may provide a transmission mechanism useful for explaining why international stock market synchronize.

We have demonstrated here a mathematical model of mode-locking between stock markets to illustrate how mode-locking can take place and to show how it can cause synchronization even with weak, variable linkages in a very noisy environment. We have demonstrated the model through simulation and have shown the ability of the model to synchronize markets under conditions of noise, random shocks, and time-varying parameters. Finally we have analyzed empirical global stock market data, using various statistical techniques, including spectral and cross-spectral analysis in order to test for the assumptions and implications of the mode-locking model. Looking at the time plot graphs, one is struck by the similarities in the movements of several of the major national stock markets. We see a relatively high degree of correlation between the growth rates of the stock market indexes of the US, Canadian, and European stock markets. The presence of linkages is revealed by Granger causality tests in which some of the markets, especially the US stock market, are shown to have causal effects on various of the other markets around the world. Nonlinearity tests show the presence of nonlinearities, a necessary condition for mode-locking synchronization to take place. Prior literature confirms the presence of deterministic processes within the stock market movements, also necessary for mode-locking. Finally, spectral and cross-spectral plots reveal a tendency toward a dominant frequency (periodicity) and a convergence of various stock markets upon a common frequency, characteristics typical of mode-locking. Thus we find that the US and European financial markets synchronize in a way consistent with the mode-locking hypothesis. This possibility of mode-locking means that even weak linkages may be sufficient to bring about a synchronization of stock markets, and that international stock markets may be increasingly synchronized. An increase in the synchronization of international stock markets implies that the benefits due to international investment diversification may be diminished in the future.

The mode-locking phenomenon may have other applications in economics, such as for examining the linkages between financial markets and the real economy.

\section{Acknowledgements}

We would like to thank Luke Watson for his help with this research project.

\section{Data Appendix}

The data for this research comes from the Global Financial Database. It is monthly national stock market index data, over the period $1967.01-2010.02$, for the following countries with their database variable names. Most of the analysis is done for stock market index growth rates as represented by the first differences of the logs of the stock market indexes.

$$
\begin{aligned}
& \text { Argentina - ibgd } \\
& \text { Brazil - bvspd } \\
& \text { Canada - gsptsed } \\
& \text { Colombia - igbcd } \\
& \text { France - sbf250d } \\
& \text { Germany - fwbxxd } \\
& \text { Italy - bciid } \\
& \text { Japan - n225d } \\
& \text { Korea - ks11d } \\
& \text { Mexico - mxxd } \\
& \text { Spain - smsid } \\
& \text { UK - ftasd } \\
& \text { US - spxd } \\
& \text { Venezuela - ibcd }
\end{aligned}
$$




\section{References}

Anderson, Heather M., \& James B. Ramsey. (2002). U.S. and Canadian Industrial Production Indices as Coupled Oscillators. Journal of Economic Dynamics and Control, 26(1), 33-67. http://dx.doi.org/10.1016/S0165-1889(00)00049-X

Arshanapalli, Bala, \& John Doukas. (1993). International stock market linkages: Evidence from the pre- and post-October 1987 period. Journal of Banking and Finance, 17, 193-208. http://dx.doi.org/10.1016/0378-4266(93)90088-U

Arshanapalli, Bala, John Doukas, \& Larry H.P. Lang. (1995). Pre- and post-October 1987 stock market linkages between U.S. and Asian markets. Pacific Basin Finance Journal, 57-73.

Asgharian, Hossein, Wolfgang Hess, \& Lu Liu. (2013). A spatial analysis of international stock market linkages. Journal of Banking \& Finance, 37, 4738-4754. http://dx.doi.org/10.1016/j.jbankfin.2013.08.015

Beine, Michel, \& Bertrand Candelon. (2007). Liberalization and Stock Market Co-Movement between Emerging Markets. CESifo Working Paper No. 2131, October 2007.

Bekaert, Geert, Campbell R. Harvey, \& Angela Ng. (2005). Market Integration and Contagion. Journal of Business, 78(1), 39-69. http://dx.doi.org/10.1086/426519

Berben, Robert-Paul, \& W. Jos Jansen. (2005). Comovement in international equity markets: A sectoral view. Journal of International Money and Finance, 24, 832-857. http://dx.doi.org/10.1016/j.jimonfin.2005.04.001

Canova, Fabio, \& Gianni De Nicolo. (1995). Stock Returns and Real Activity: A Structural Approach. European Economic Review, 39, 981-1015. http://dx.doi.org/10.1016/0014-2921(95)00017-8

Doan, Thomas A. (2010). RATS Version 8.0. Evanston, IL: Estima.

Eun, Cheol S., \& Sangdal Shim. (1989, June). International Transmission of Stock Market Movements. The Journal of Financial and Quantitative Analysis, 24(2), 241-256. http://dx.doi.org/10.2307/2330774

Fama, Eugene F. (1981). Stock Returns, Real Activity, Inflation, and Money. American Economic Review, 71(4), 545-565.

Fama, Eugene F. (1990). Stock Returns, Expected Returns, and Real Activity. Journal of Finance, 45(4), 1089-1108.

Flavin, Thomas J., Margaret J. Hurley, \& Fabrice Rousseau. (2002). Explaining Stock Market Correlation: A Gravity Model Approach. The Manchester School Supplement, 87-106. http://dx.doi.org/10.1111/1467-9957.70.s1.5

Forbes, Kristin J., \& Roberto Rigobon. (2001). Measuring contagion: Conceptual and empirical issues. In Stijn Claessens and Kristin J. Forbes (Eds.), International Financial Contagion (Chapter 3). Norwell, MA: Kluwer Academic Publishers. http://dx.doi.org/10.1007/978-1-4757-3314-3_3

Forbes, Kristin J., \& Menzie D. Chinn. (2004). A Decomposition of Global Linkages in Financial Markets Over Time. The Review of Economics and Statistics, 86(3), 705-722. http://dx.doi.org/10.1162/0034653041811743

Forbes, Kristin J., \& Roberto Rigobon. (2002). No Contagion, Only Interdependence: Measuring Stock Market Comovements. Journal of Finance, 57(5), 2223-2261. http://dx.doi.org/10.1111/0022-1082.00494

Gleick, J. (1987). Chaos: Making a new science. Viking Penguin, New York.

Granger, Clive W.J., \& Oskar. Morgenstern. (1970). Predictability of Stock Market Prices. Lexington, MA: Heath Lexington Books.

Grubel, Herbert G. (1968). Internationally Diversified Portfolios: Welfare Gains and Capital Flows. American Economic Review, 58(5), 1299-1314.

Hamao, Yasushi, Ronald W. Masulis, \& Victor Ng. (1990). Correlations in Price Changes and Volatility across International Stock Markets. The Review of Financial Studies, 3(2), 281-307. http://dx.doi.org/10.1093/rfs/3.2.281

Hilliard, Jimmy E. (1979). The Relationship Between Equity Indices on World Exchanges. Journal of Finance, 34(1), 103-114. http://dx.doi.org/10.1111/j.1540-6261.1979.tb02074.x

Hu, John Wei-Shan, Mei-Yuan Chen, Robert C.W. Fok, \& Bwo-Nung Huang. (1997). Causality in volatility and volatility spillover effects between US, Japan, and four equity markets in the South China Growth Triangular. Journal of International Financial Markets, Institutions and Money, 7, 351-367.

Karolyi, G. Andrew, \& René M. Stulz. (1996). Why Do Markets Move Together? An Investigation of U.S.-Japan Stock Return Comovements. The Journal of Finance, 51(3), 951-986. http://dx.doi.org/10.1111/j.1540-6261.1996.tb02713.x 
Kasa, Kenneth. (1992). Common stochastic trends in international stock markets. Journal of Monetary Economics, 29, 95-124. http://dx.doi.org/10.1016/0304-3932(92)90025-W

King, Mervyn A., \& Sushil Wadhwani. (1990). Transmission of Volatility between Stock Markets. The Review of Financial Studies, 3(1), 5-33. http://dx.doi.org/10.1093/rfs/3.1.5

Kizys, Renatas, \& Christian Pierdzioch. (2009). Changes in the international comovement of stock returns and asymmetric macroeconomic shocks. Journal of International Financial Markets, Institutions \& Money, 19, 289-305. http://dx.doi.org/10.1016/j.intfin.2008.01.002

Krugman, Paul. (1996). The Self-Organizing Economy. Cambridge, MA: Blackwell Publishers.

Lahrech, Abdelmounaim, \& Kevin Sylwester. (2013). The impact of NAFTA on North American stock market linkages. North American Journal of Economics and Finance, 25, 94-108.

Liu, Lu. (2013). International stock market interdependence: Are developing markets the same as developed markets? Journal of International Financial Markets, Institutions \& Money, 26, 226-238.

Lucey, Brian M., \& Qi Yu Zhang. (2010). Does cultural distance matter in international stock market comovement? Evidence from emerging economies around the world. Emerging Markets Review, 11, 62-78.

Masih, Abul M.M., \& Rumi Masih. (1997). Dynamic Linkages and the Propagation Mechanism Driving Major International Stock Markets: An Analysis of the Pre- and Post-Crash Eras. The Quarterly Review of Economics and Statistics, 37(4), Fall, 859-885.

Masih, Abul M.M., \& Rumi Masih. (1999). Are Asian stock market fluctuations due mainly to intra-regional contagion effects? Evidence based on Asian emerging stock markets. Pacific-Basin Financial Journal, 7 , 251-282. http://dx.doi.org/10.1016/S0927-538X(99)00013-X

Mosekilde, E., E.R. Larsen, J.D. Sterman, \& J.S. Thomsen. (1992). Mode locking and nonlinear entrainment of macroeconomic cycles. In R.H. Day, and P. Cheng (Eds.), Nonlinear dynamics and evolutionary economics.

Mosekilde, E., E.R. Larsen, J.D. Sterman, \& J.S. Thomsen. (1992). Nonlinear mode-interaction in the macroeconomy. Annals of Operations Research, 37, 185-215. http://dx.doi.org/10.1007/BF02071056

Mosekilde, E., J.S. Thomsen, \& J. Sterman. (1992). Nonlinear interactions in the economy. In G. Haag, U. Mueller and K.G. Troitzsch (Eds.), Economic evolution and demographic change. Springer-Verlag, Berlin, Germany.

Pretorius, Elna. (2002). Economic determinants of emerging stock market interdependence. Emerging Markets Review, 3, 84-105. http://dx.doi.org/10.1016/S1566-0141(01)00032-2

Quinn, Dennis P., \& Hans-Joachim Voth. (2008). A Century of Global Equity Market Correlations. American Economic Review, 98(2), 535-540. http://dx.doi.org/10.1257/aer.98.2.535

Ramchand, Latha, \& Raul Susmel. (1998). Volatility and cross correlation across major stock markets. Journal of Empirical Finance, 5, 397-416. http://dx.doi.org/10.1016/S0927-5398(98)00003-6

Rua, António, \& Luís C. Nunes. (2009). International comovement of stock market returns: A wavelet analysis. Journal of Empirical Finance, 16, 632-639. http://dx.doi.org/10.1016/j.jempfin.2009.02.002

Scharfstein, David S., \& Jeremy C. Stein. (1990). Herd Behavior and Investment. The American Economic Review, $80,495-479$.

Selover, David D., \& Roderick V. Jensen. (1999). 'Mode-Locking' and International Business Cycle Transmission. Journal of Economic Dynamics and Control, 23, 591-618. http://dx.doi.org/10.1016/S0165-1889(98)00036-0

Selover, David D., Roderick V. Jensen, \& John Kroll. (2003, October). Industrial Sector Mode-Locking and Business Cycle Formation. Studies in Nonlinear Dynamics and Econometrics.

Selover, David D., Roderick V. Jensen, \& John Kroll. (2005). Mode-Locking and Regional Business Cycle Synchronization. Journal of Regional Science, 45(4), 703-745.

Strogatz, Steven. (2003). Sync: The Emerging Science of Spontaneous Order. New York: Hyperion Books.

Strogatz, S.H. (1994). Nonlinear dynamics and chaos. Addison-Wesley Publishing Company, Reading, MA.

Süssmuth, Bernd. (2002). Can Herding Explain Cyclic Co-Movement? International Game Theory Review, 4(1), 33-51. http://dx.doi.org/10.1142/S0219198902000537

Süssmuth, Bernd. (2003). Modeling the synchronization of sectoral investment cycles on the base of informational externalities. Structural Change and Economic Dynamics, 14, 35-54. 
Süssmuth, Bernd, \& Ulrich Woitek. (2004). Business Cycles and Comovement in Mediterranean Economies: A National and Areawide Perspective. Emerging Markets Finance and Trade, 40(6), 7-27.

Süssmuth, Bernd, \& Ulrich Woitek. (2005). Some New Results on Industrial Sector Mode-Locking and Business Cycle Formation. Studies in Nonlinear Dynamics \& Econometrics, 9(3), 1-33.

Thompson, Rory O. R. Y. (1979). Coherence Significance Levels. Journal of Atmospheric Sciences, 36, 2020-2021.

Weser, Thilo. (1992). The Aggregation Problem for Economic Cycles. In Hillinger, Claude (Ed.), Cyclical Growth in Market and Planned Economies. Oxford: Clarendon Press.

Woitek, Ulrich. (1996). The G7 Countries: A Multivariate Description of the Business Cycle Stylized Facts. In Barnett, William A., Gandolfo, Giancarlo, \& Hillinger, Claude (Eds.). Dynamic Disequilibrium Modelling: Theory and Applications (1996). Cambridge: Cambridge University Press.

\section{Notes}

Note 1. The mode-locking concept can be generalized to $n$ markets.

Note 2. From Gleick (1987).

Note 3. The phase differential may be zero with the two stock markets synchronized perfectly in phase, or it may be non-zero, indicating a lag or lead.

Note 4. Many possible nonlinear oscillators could be chosen as examples. The mode-locking phenomenon is not contingent upon the existence of a van der Pol oscillator stock market.

Note 5. The $\mathrm{r}$ parameter will play a minor but complex role in the determination of the frequency. In practice it does not significantly affect the frequency for $r<0.7$. For our purposes we will assume $r$ to be small.

Note 6 . The linkage can be nonlinear as well, but in this model the linkage is linear.

Note 7. One can view these linkages as forcing terms, and they are thus more easily interpreted on the right hand side of the equation. On the right hand side of the equation the coefficient is positive, and thus in the first equation $y$ should force $\mathrm{x}$ in the same direction as $\mathrm{y}$. In the second equation, $\mathrm{x}$ should force $\mathrm{y}$ in the same direction as $\mathrm{x}$.

Note 8. The simulations were performed using Mathematica 4.0, Wolfram (1999).

Note 9. Once again, when we refer to synchronization, there may be a phase difference.

Note 10. This pattern of correlations between stock market growth rates is confirmed by principal components analysis in which the first component loads largely on the US, Canada, Europe, Mexico, Japan, and Korea, while the second component loads mainly on the South American markets.

Note 11. Kasa (1992), Arshanapalli and Doukas (1993), Arshanapalli, Doukas, and Lang (1995), and Masih and Masih $(1997,1999)$ have found certain international stock markets to be cointegrated. However, these papers do not make clear what the mechanism might be that enforces such a cointegrating relationship. International stock markets are not likely to have a long-run dynamic equilibrium with each other. We tested for cointegration but found little evidence of cointegration between national stock markets.

Note 12. We also performed BDS (Brock, Dechert, and Scheinkman) tests for nonlinearity, and the stock market returns for all the markets tested (except Argentina) were found to exhibit nonlinearities. However, the BDS test has power against many other alternatives.

Note 13. The spectral and cross-spectral analysis was done using RATS 8.0, and programs from the Estima RATS Forum website (www.estima.com) were used and modified for the analysis here. There were 506 total observations padded to 786 ordinates and estimated with a flat window of width 21, using data 1968.01 to 2011.02.

Note 14. We are only interested in frequencies between zero and one, that is, fluctuations of greater than one year in length. One year fluctuations are generally due to seasonal effects, either weather related or holiday effects.

Note 15 . The $95 \%$ confidence intervals have been produced using the asymptotic distribution formula, the d.f. and the $\chi^{2}$ distribution critical values: $-\log \left(d f / \chi_{.025, d f}^{2}\right)$ and $+\log \left(d f / \chi_{.975, d f}^{2}\right)$ where $\mathrm{df}=21$ is the window size of the estimator. These asymptotic confidence intervals are somewhat wider but more stable than bootstrapped confidence intervals.

Note 16. The 0.05 critical value for the cross-spectral coherence is given by the formula, $(.05)=\sqrt{1-\alpha^{1 /(n-1)}}$, where $\alpha$ is the size of the test 0.05 and $\mathrm{n}$ is the window size, 10 , such that $\mathrm{c}(.05)=0.532$, Thompson (1979). 